\title{
Reduced-complexity air quality intervention modeling over China: the development of InMAPv1.6.1-China and a comparison with CMAQv5.2
}

\author{
Ruili Wu ${ }^{1,2}$, Christopher W. Tessum ${ }^{3}$, Yang Zhang ${ }^{4}$, Chaopeng Hong ${ }^{5}$, Yixuan Zheng ${ }^{6}$, Xinyin Qin ${ }^{1}$, Shigan Liu $^{1}$, and \\ Qiang Zhang ${ }^{1}$ \\ ${ }^{1}$ Ministry of Education Key Laboratory for Earth System Modeling, Department of Earth System Science, \\ Tsinghua University, Beijing 100084, China \\ ${ }^{2}$ State Environmental Protection Key Laboratory of Quality Control in Environmental Monitoring, \\ China National Environmental Monitoring Centre, Beijing 100012, China \\ ${ }^{3}$ Department of Civil and Environmental Engineering, the University of Illinois at Urbana-Champaign, \\ Urbana, Illinois 61801, USA \\ ${ }^{4}$ Department of Civil and Environmental Engineering, Northeastern University, \\ Boston, Massachusetts 02115, USA \\ ${ }^{5}$ Institute of Environment and Ecology, Tsinghua Shenzhen International Graduate School, \\ Tsinghua University, Shenzhen 518055, China \\ ${ }^{6}$ Center of Air Quality Simulation and System Analysis, Chinese Academy of Environmental Planning, \\ Beijing 100012, China
}

Correspondence: Ruili Wu (wurl15@tsinghua.org.cn, wurl@cnemc.cn)

Received: 21 March 2021 - Discussion started: 26 April 2021

Revised: 20 October 2021 - Accepted: 10 November 2021 - Published: 16 December 2021

\begin{abstract}
This paper presents the first development and evaluation of a reduced-complexity air quality model for China. In this study, the reduced-complexity Intervention Model for Air Pollution over China (InMAP-China) is developed by linking a regional air quality model, a reduced-complexity air quality model, an emission inventory database for China, and a health impact assessment model to rapidly estimate the air quality and health impacts of emission sources in China. The modeling system is applied over mainland China for 2017 under various emission scenarios. A comprehensive model evaluation is conducted by comparison against conventional Community Multiscale Air Quality (CMAQ) modeling system simulations and ground-based observations. We found that InMAP-China satisfactorily predicted total $\mathrm{PM}_{2.5}$ concentrations in terms of statistical performance. Compared with the observed $\mathrm{PM}_{2.5}$ concentrations, the mean bias (MB), normalized mean bias (NMB) and correlations of the total $\mathrm{PM}_{2.5}$ concentrations are $-8.1 \mu \mathrm{g} \mathrm{m}^{-3},-18 \%$ and 0.6 , respectively. The statistical performance is considered to
\end{abstract}

be satisfactory for a reduced-complexity air quality model and remains consistent with that evaluated in the USA. The underestimation of total $\mathrm{PM}_{2.5}$ concentrations was mainly caused by its composition, primary $\mathrm{PM}_{2.5}$. In terms of the ability to quantify source contributions of $\mathrm{PM}_{2.5}$ concentrations, InMAP-China presents similar results to those based on the CMAQ model, with variation mainly caused by the different treatment of secondary inorganic aerosols in the two models. Focusing on the health impacts, the annual $\mathrm{PM}_{2.5^{-}}$ related premature mortality estimated using InMAP-China in 2017 was 1.92 million, which was 250000 deaths lower than estimated based on CMAQ simulations as a result of the underestimation of $\mathrm{PM}_{2.5}$ concentrations. This work presents a version of the reduced-complexity air quality model over China that provides a powerful tool to rapidly assess the air quality and health impacts associated with control policy and to quantify the source contribution attributable to many emission sources. 


\section{Introduction}

With rapid urbanization and industrialization, fine particulate matter pollution less than $2.5 \mu \mathrm{m}$ in diameter $\left(\mathrm{PM}_{2.5}\right)$ has become a major environmental issue in China. High $\mathrm{PM}_{2.5}$ concentrations can be observed over eastern China from satellite observations (Xiao et al., 2020); however, $\mathrm{PM}_{2.5}$ concentrations have largely decreased since 2013 due to the effective control measures taken by the Chinese government (Zhao et al., 2021). $\mathrm{PM}_{2.5}$ can affect air quality, ecosystems, and climate change, and it can also damage human health via shortterm or long-term exposure. The Global Burden of Disease (GBD) study reported that 1.1 million premature deaths were caused by long-term $\mathrm{PM}_{2.5}$ exposure over China in 2015 (Cohen et al., 2017).

State-of-the-art three-dimensional air quality models (AQMs) have been widely used in China as tools to simulate regional $\mathrm{PM}_{2.5}$ concentrations, quantify the contributions to total $\mathrm{PM}_{2.5}$ concentrations resulting from emission sources and assess the benefits associated with control measures (Chang et al., 2019; Li et al., 2015; Zhang et al., 2015, 2019). The Weather Research and ForecastingCommunity Multiscale Air Quality (WRF-CMAQ) modeling system (Appel et al., 2018; Chang et al., 2019), the Weather Research and Forecasting model coupled with Chemistry (WRF-Chem) (Reddington et al., 2019), the Weather Research and Forecasting-Comprehensive Air Quality Model Extension (WRF-CAMx) modeling system (Li et al., 2015), and the adjoint of global chemistry model GEOS-Chem (GEOS-Chem Adjoint) (Zhang et al., 2015) have been frequently used in previous studies. To conduct a series of simulations for multiple scenarios or quantify the separate contributions attributable to multiple sources, large computational resources and runtimes are required when utilizing conventional AQMs. To address these challenges and to improve the availability and accessibility of air quality modeling, several reduced-complexity models have been developed by the air quality research community. The three representative reduced-complexity air quality models frequently used are the Estimating Air Pollution Social Impact Using Regression (EASIUR) model (Heo et al., 2016, 2017), the updated Air Pollution Emission Experiments and Policy (APEEP2) model (Muller and Mendelsohn, 2007; Muller et al., 2011) and the Intervention Model for Air Pollution (InMAP) (Tessum et al., 2017). A recent study compared three reducedcomplexity models, EASIUR, APEEP2, and InMAP, and the results indicate that these three models are consistent in their assessment of the marginal social cost at the county level (Gilmore et al., 2019). Reduced-complexity air quality models are less computationally intensive and easier to use. However, no such model is currently available for China. Therefore, it is essential to develop a reduced-complexity air quality model over China to quickly predict $\mathrm{PM}_{2.5}$ concentrations and the associated health impacts of emission sources.
The reduced-complexity Intervention Model for Air Pollution (InMAP) was developed by Tessum et al. (2017) to rapidly assess the air pollution, health and economic impacts resulting from marginal changes in air pollutant emissions. Compared with conventional air quality models, InMAP has the advantage of being temporally efficient: it can predict annual average $\mathrm{PM}_{2.5}$ concentrations within a few hours with only a modest reduction in accuracy compared with chemistry transport models (CTMs). InMAP reduces the runtime by simplifying the physical and chemical processes, and it has been used to assess marginal health damage of locationspecific emission sources (Goodkind et al., 2019), to quantify the health impacts of individual coal-fired power plants in the USA (Thind et al., 2019) and to estimate the health benefits of control policies with respect to specific locations (Sergi et al., 2020). However, to date, a version of the reducedcomplexity Intervention Model for Air Pollution for China is absent.

In this work, based on the source code of version 1.6.1 of InMAP, the reduced-complexity Intervention Model for Air Pollution over China (InMAP-China) is developed to rapidly predict the air quality and estimate the health impacts of emission sources in China. The total simulation time for the year 2017 using the InMAP-China model established in this study is approximately $1 \mathrm{~h}$ with a single 24-node central processing unit (CPU). Therefore, this model is convenient when conducting multiple simulations of $\mathrm{PM}_{2.5}$ concentrations due to air pollutant emissions in 2017. The modeling system is applied over mainland China for 2017 under various emission scenarios to examine model performance. Comparisons against conventional air quality models and surface observations are performed in this study. The model applicability and limitations are also declared.

The paper is organized as follows: Sect. 2.1 presents the components of InMAP-China, including the interface development between WRF-CMAQ and InMAP to generate the base atmospheric state parameters, the preprocessing process for emission input data and the exposure-response functions employed in this model; Sect. 2.2 introduces the evaluation protocol, including the statistical variables adopted and the simulation design in this study; Sect. 3 presents the evaluation of the InMAP-China predictions of $\mathrm{PM}_{2.5}$ air quality and $\mathrm{PM}_{2.5}$-related health impacts in several simulations; and, finally, Sect. 4 summarizes the conclusions and limitations of this study.

\section{Description of the InMAP-China model}

\subsection{Model components and configurations}

InMAP has been widely used in studies (Sergi et al., 2020; Thind et al., 2019; Goodkind et al., 2019; Dimanchevi et al., 2019) focusing on $\mathrm{PM}_{2.5}$ pollution as well as health and economic impacts resulting from emission sources in the USA. 
In this model, the continuous equation of atmospheric pollutants is solved at an annual scale, and the runtime can be reduced. The parameters used to represent physical and chemical processes for simplified simulation are calculated beforehand using CTM output data. $\mathrm{PM}_{2.5}$ air quality and $\mathrm{PM}_{2.5}$ related premature mortality are predicted and output in the InMAP model.

In this work, a Chinese version of the reduced-complexity Intervention Model for Air Pollution (InMAP-China) is developed to rapidly estimate the $\mathrm{PM}_{2.5}$ concentration and associated health impacts of emission sources. Figure 1 shows the model framework. Based on the source code of the InMAP model, three-step development work is conducted to establish InMAP-China. First, we develop a preprocessed interface to calculate physical and chemical process parameters using WRF-CMAQ output variables to support the simplified simulation in InMAP-China. Second, air pollutant emission data are preprocessed to an appropriate format for the InMAP-China simulation. Third, the exposure-response function of the Global Exposure Mortality Model (GEMM) is employed in InMAP-China and replaces the original default function to assess $\mathrm{PM}_{2.5}$-related health impacts.

Table 1 presents the basic configurations of InMAP-China. The simulation domain is over East Asia and covers mainland China. The spatial resolution is $36 \mathrm{~km}$. Fourteen vertical layers are used in InMAP-China, ranging from the surface layer to the top level of the tropospheric layer.

\subsubsection{Parameter interface development for simplified simulation in InMAP-China}

We develop a preprocessed interface to calculate physical and chemical process parameters using WRF-CMAQ output variables for simplified simulation in InMAP-China based on work from the Environmental Protection Agency (EPA) (Baker et al., 2020). Two NetCDF (Network Common Data Form) files containing the key parameters for simplified simulation are generated using the parameter interface developed here: one is at a $36 \mathrm{~km}$ resolution across the entire mainland of China and another is at a $4 \mathrm{~km}$ resolution over the Beijing-Tianjin-Hebei (BTH) region. The main step of the preprocessed interface includes meteorological and chemical variable extraction and merging, unit conversion, vertical layer mapping, physical and chemical process parameter calculation, and average processing. The hourly chemical and meteorological variable outputs from the WRF-CMAQ modeling system are converted into the annual average physical and chemical process parameters required for simplified simulation.

A NetCDF file containing the three-dimensional annually averaged parameters to characterize atmospheric advection, dispersion, mixing, chemical reaction and deposition is generated. Table 2 shows the relationship between the annually averaged parameters for simplified simulation and the original hourly variables. In InMAP-China, the annually aver- aged component and the deviation of wind speed to represent advection are calculated using hourly elements. The offset of wind vectors in different directions may result in some uncertainties in this process. The parameters of eddy diffusion and convective transport are pre-calculated using hourly elements, including temperature, pressure and boundary layer height, among others. The annual wet deposition rate is determined by the rainwater mixing ratio and cloud fractions. The annual dry deposition rate of particles and gaseous pollutants at the surface level is pre-calculated using friction speed, heat flux, radiation flux and land cover. The simplification of chemical reactions is different among pollutants. For $\mathrm{NO}_{x}, \mathrm{NH}_{3}$ and volatile organic compound (VOC) precursors, the annual average gas-particle partitioning is adopted and calculated before using the output concentrations of species from CMAQ. For $\mathrm{SO}_{2}$ pollutants, the annual oxidation rate of two major conversion pathways for $\mathrm{SO}_{2}$ is calculated using concentrations of the hydroxyl radical $(\mathrm{HO})$ and hydrogen peroxide $\left(\mathrm{H}_{2} \mathrm{O}_{2}\right)$ in $\mathrm{CMAQ}$, and the conversion is estimated in InMAP-China.

\subsubsection{Prior WRF-CMAQ simulation}

To generate the meteorological and chemical parameters required by InMAP-China, a 1-year WRF-CMAQ simulation covering the entirety of mainland of China is conducted to output hourly meteorological and chemistry-related variables in 2017. Furthermore, a nested WRF-CMAQ simulation over the BTH region is also conducted and validated using observed data. The corresponded output data are used to generate the meteorological and chemical parameters required by InMAP-China for the $4 \mathrm{~km}$ resolution simulations in the BTH region. Tables S1 and S2 in the Supplement show the major configurations of the WRF-CMAQ modeling system. The WRF model (Skamarock et al., 2008) is driven by the National Centers for Environmental Prediction Final Analysis (NCEP-FNL) (https://doi.org/10.5065/D6M043C6; National Centers for Environmental Prediction, 2000) reanalysis data to provide the initial and boundary conditions. The meteorological fields derived from the WRF model are used to drive the CMAQ model (Appel et al., 2018) simulations. The air pollutant emissions used here include anthropogenic emissions over China derived from the Multiresolution Emission Inventory for China (MEIC) model (http://meicmodel.org/, last access: 9 December 2021), anthropogenic emissions over the region of East Asia outside China derived from the MIX-2010 (a mosaic Asian anthropogenic emission inventory) inventory (Li et al., 2017) and biogenic emissions derived from the Model of Emissions of Gases and Aerosols from Nature (MEGAN) v2.10 model. The Carbon Bond 05 (CB05) mechanism and the aerosols 6 (AERO6) module are employed in the model simulation.

Table S3 summarizes the performance statistics of meteorological variables, including surface temperature, relative humidity and wind speed, in China in 2017, as simulated by 
InMAP-China model

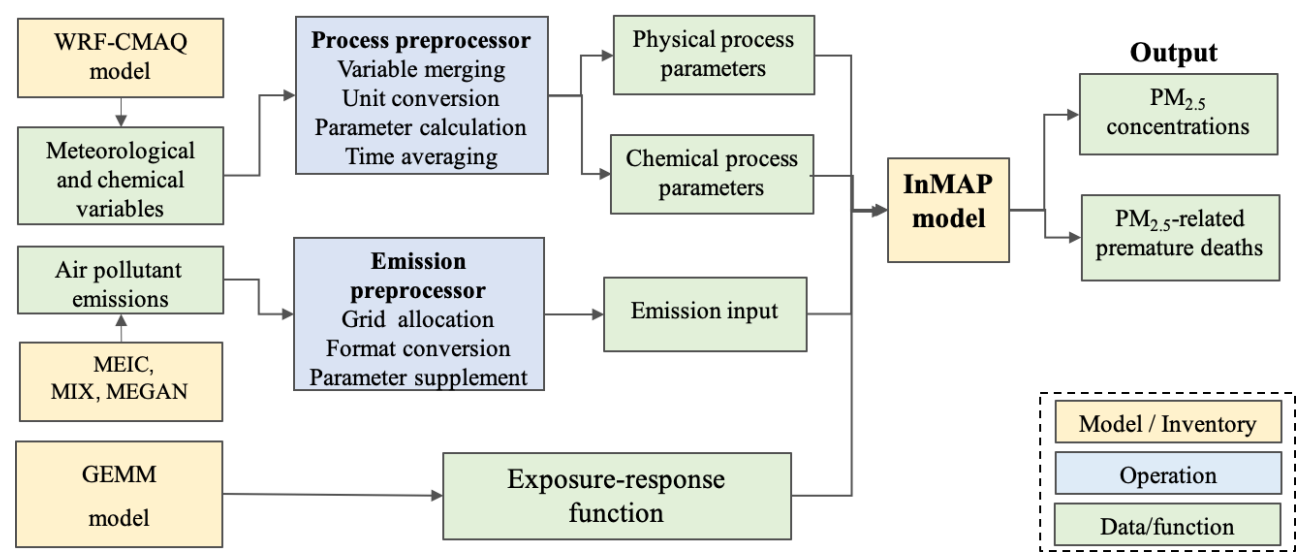

Figure 1. Model framework of InMAP-China.

Table 1. Model configurations in InMAP-China.

\begin{tabular}{lll}
\hline Category & Parameters & Configurations \\
\hline Basic & Research area and period & China, 2017 \\
& Spatial resolution & $36 \mathrm{~km} \times 36 \mathrm{~km}$ \\
& Vertical layers & 14 layers \\
& Run type & Steady run \\
& Variable grid & Static grid \\
& Projection & Lambert \\
& Grid numbers & 305816 \\
\hline Input & Meteorological and chemical parameters & Calculated using variables from WRFv3.8-CMAQv5.2 \\
& Anthropogenic emissions & MEIC, MIX, MEGAN \\
& Population data & GPW 2015 and GBD 2017 \\
& Baseline mortality rate & GBD 2017 \\
\hline \multirow{2}{*}{ Output } & Air pollutants & PM 2.5 and its composition concentrations \\
& Mortality & PM 2.5 -related premature mortality \\
\hline
\end{tabular}

the WRF model. The hourly observed data of major meteorological variables derived from the National Climatic Data Center (NCDC) are utilized here. The results show that the meteorological variables simulated by the WRF model agree well with the surface observations, which is consistent with previous studies (Wu et al., 2019; Zheng et al., 2015; Hong et al., 2017). The model performs well with respect to the prediction of surface temperature, with a mean bias (MB) of $-0.7 \mathrm{~K}$, a normalized mean bias (NMB) of $-6.1 \%$ and an $R$ value of 0.9 . The predictions of relative humidity at a height of $2 \mathrm{~m}$ are relatively satisfactory with an MB of $4.1 \%$ and an NMB of $6.1 \%$. The predictions of wind speed at a height of $10 \mathrm{~m}$ are slightly overestimated, with an MB of $0.3 \mathrm{~m} \mathrm{~s}^{-1}$ and an NMB of $12.4 \%$, which may be caused by out-of-date United States Geological Survey (USGS) land use data employed in the model runs.

The $\mathrm{SO}_{2}, \mathrm{NO}_{2}$ and $\mathrm{PM}_{2.5}$ concentrations modeled across the domain agree well with the surface observations in terms of the statistical performance and monthly variations. Table S4 summarizes the performance of the statistics of major air pollutant concentrations. The nationwide annual average $\mathrm{PM}_{2.5}$ concentration simulated in China in 2017 was $42.1 \mu \mathrm{g} \mathrm{m}^{-3}$. Compared with the observed $\mathrm{PM}_{2.5}$ of $45.9 \mu \mathrm{g} \mathrm{m}^{-3}$, there are slight underpredictions, with an MB of $3.7 \mu \mathrm{g} \mathrm{m}^{-3}$ and an NMB of $8.1 \%$. The CMAQ model shows moderate underpredictions of the $\mathrm{NO}_{2}$ and $\mathrm{SO}_{2}$ concentrations, which may be related to the uncertainties in the emission inputs. For modeled $\mathrm{NO}_{2}$ concentrations, the $\mathrm{MB}$ and $\mathrm{NMB}$ are $-4.6 \mu \mathrm{g} \mathrm{m}^{-3}$ and $-13.9 \%$, respectively. For modeled $\mathrm{SO}_{2}$ concentrations, $\mathrm{MB}$ and $\mathrm{NMB}$ are $-0.8 \mu \mathrm{g} \mathrm{m}^{-3}$ and $-4.5 \%$, respectively. Figure $\mathrm{S} 3$ shows the monthly variation. The variation trend in the observed $\mathrm{SO}_{2}, \mathrm{NO}_{2}$ and $\mathrm{PM}_{2.5}$ concentrations can be reproduced in the CMAQ simulations. 
Table 2. The relationship between parameters for simplified simulation and original variables.

\begin{tabular}{|c|c|c|c|}
\hline $\begin{array}{l}\text { WRF-CMAQ } \\
\text { variables }\end{array}$ & Description & InMAP-China parameters & Description \\
\hline$U, V, W$ & Wind fields & $\begin{array}{l}\text { UAvg, UDeviation VAvg, VDe- } \\
\text { viation WAvg, WDeviation }\end{array}$ & Advection and mixing coefficients \\
\hline PH, PHB & $\begin{array}{l}\text { Base state of geopotential and per- } \\
\text { turbation geopotential }\end{array}$ & $\mathrm{Dz}$ & Layer heights \\
\hline PBLH & Planetary boundary layer height & M2d, M2u, Kxxyy, Kzz & Mixing coefficients \\
\hline$T$ & Potential temperature & \multirow[t]{2}{*}{$\mathrm{SO}_{2}$ Oxidation, PlumeHeight } & $\begin{array}{l}\text { Chemical reaction rates and plume } \\
\text { rise }\end{array}$ \\
\hline$P, \mathrm{~PB}$ & $\begin{array}{l}\text { Base state pressure plus } \\
\text { perturbation pressure }\end{array}$ & & $\begin{array}{l}\text { Chemical reaction rates and plume } \\
\text { rise }\end{array}$ \\
\hline QRAIN & Mixing ratio of rain & ParticleWetdep, GasWetdep & Wet deposition \\
\hline QCLOUD & Cloud mixing ratio & $\mathrm{SO}_{2}$ Oxidation & $\begin{array}{l}\text { Aqueous-phase chemical reaction } \\
\text { rates }\end{array}$ \\
\hline CLDFRA & $\begin{array}{l}\text { Fraction of grid cell covered by } \\
\text { clouds }\end{array}$ & ParticleWetdep, GasWetdep & Wet deposition \\
\hline $\begin{array}{l}\text { SWDOWN, } \\
\text { GLW }\end{array}$ & $\begin{array}{l}\text { Downward shortwave and long- } \\
\text { wave radiative flux at ground level }\end{array}$ & GasDrydep, ParticleWetdep & Dry deposition \\
\hline HFX & Surface heat flux & \multirow{2}{*}{$\begin{array}{l}\text { M2d, M2u, Kxxyy, Kzz, } \\
\text { Drydep }\end{array}$} & Mixing and dry deposition \\
\hline UST & Friction velocity & & Mixing and dry deposition \\
\hline LU_INDEX & Land use type & \multirow[t]{2}{*}{ M2d, M2u, Kxxyy, Kzz } & Mixing \\
\hline DENS & Inverse air density & & $\begin{array}{l}\text { Mixing and convert between mix- } \\
\text { ing ratio and mass concentration }\end{array}$ \\
\hline $\mathrm{aVOC}$ & $\begin{array}{l}\text { Anthropogenic VOCs that are sec- } \\
\text { ondary organic aerosol (SOA) pre- } \\
\text { cursors }\end{array}$ & \multirow[t]{2}{*}{ aOrgPartitioning } & VOC/SOA partitioning \\
\hline aSOA & Anthropogenic SOA & & \\
\hline $\mathrm{OH}, \mathrm{H}_{2} \mathrm{O}_{2}$ & $\begin{array}{l}\text { Hydroxyl radical and hydrogen per- } \\
\text { oxide concentrations }\end{array}$ & $\mathrm{SO}_{2}$ Oxidation & Oxidation rates \\
\hline $\mathrm{pNO}$ & $\mathrm{ANO}_{3} \mathrm{I}, \mathrm{ANO}_{3} \mathrm{~J}$ & \multirow[t]{2}{*}{ NOPartitioning } & $\mathrm{NO}_{x} / \mathrm{pNO}_{3}$ partitioning \\
\hline gNO & $\mathrm{NO}$ and $\mathrm{NO}_{2}$ & & \\
\hline $\mathrm{pNH}$ & $\mathrm{ANH}_{4} \mathrm{I}, \mathrm{ANH}_{4} \mathrm{~J}$ & \multirow[t]{2}{*}{ NHPartitioning } & $\mathrm{NH}_{3} / \mathrm{pNH}_{4}$ partitioning \\
\hline gNH & $\mathrm{NH}_{3}$ & & \\
\hline
\end{tabular}

\subsubsection{Preprocessed emission input data}

We develop the preprocessed module to generate vector emission input for the InMAP-China simulation. This module can allocate air pollutant emissions to vertically and horizontally supply the missing parameters for the emission file and convert them into a shapefile vector format. The shapefile vector format's $36 \mathrm{~km}$ resolution emission data for the entirety of mainland of China and $4 \mathrm{~km}$ resolution data for the BTH region in 2017 are preprocessed using this module.
In this module, the emission data are preprocessed by source and altitude. The anthropogenic emissions of five sectors in China in 2017 from the MEIC inventory (http: //meicmodel.org/, last access: 9 December 2021; Liu et al., 2015), the anthropogenic emissions over Asian regions outside of mainland China from the MIX-2010 inventory ( $\mathrm{Li}$ et al., 2017) and the natural emissions estimated using the MEGANv2.10 model (Guenther et al., 2012) are employed in this study.

In more detail, the $0.3^{\circ}$ gridded anthropogenic emissions for the residential, transportation and agricultural sectors are 
preprocessed and input to the surface layer. The gridded air pollutant emissions for the industrial sector and noncoal power plants are preprocessed for allocation to attitudes ranging from 130 to $240 \mathrm{~m}$ and from 130 to $890 \mathrm{~m}$, respectively. The emissions from coal-fired power plants (CPPs) are preprocessed as point sources. The air pollutant emissions and the stack attribution of each unit are provided in the emission file. Because the stack attribution of the power unit is not provided in the MEIC inventory, we supplied the information in the preprocessed module based on NEI (National Emissions Inventory) data of power units (United States Environmental Protection Agency, 2011). For the stack height/stack diameter, a linear relationship is first established (see Fig. S1); supplementation of these two parameters for Chinese power plants is then conducted using the relationships. A fixed value for the other two stack attribution variables is set here because the $\mathrm{PM}_{2.5}$ concentrations attributable to power plants (CPP-PM $\left.{ }_{2.5}\right)$ are less sensitive to these two variables (see Fig. S2). The stack gas exit velocity and stack gas exit temperature of the power unit are $6 \mathrm{~m} \mathrm{~s}^{-1}$ and $313 \mathrm{~K}$, respectively. The air pollutant emissions over Asian regions outside of mainland China and the natural emissions simulated by MEGANv2.10 are preprocessed and input to the surface layer.

\subsubsection{Exposure-response function from GEMM}

To rapidly estimate the premature mortality attributable to $\mathrm{PM}_{2.5}$ exposure, we employ the exposure-response function from GEMM, developed by Burnett et al. (2018), to estimate $\mathrm{PM}_{2.5}$-related premature mortality. The $\mathrm{PM}_{2.5}$ concentration predicted by InMAP-China is also utilized in the estimation of premature mortality. Premature mortality due to noncommunicable diseases (NCDs) and lower respiratory infections (LRIs) was considered in this study. Mortality is determined by the mortality incidence rate, the population and the attributable fraction (AF) to certain $\mathrm{PM}_{2.5}$ concentrations. The national mortality incidence rate and the population data were derived from the GBD 2017 study (Institute for Health Metrics and Evaluation; Global Burden of Disease Collaborative Network, 2018a, b). The spatial distribution of the population in 2015 from the Gridded Population of World (GPW) version 4 (Doxsey et al., 2015) was employed to allocate the population in 2017.

\subsection{Evaluation protocol}

\subsubsection{Evaluation method}

In this study, the performance of the InMAP-China predictions are evaluated by comparison against CMAQ simulations and surface observations. Model-model and modelobservation comparison have both been used to evaluate the performance of reduced-complexity air quality models in previous studies (Tessum et al., 2017; Gilmore et al., 2019).

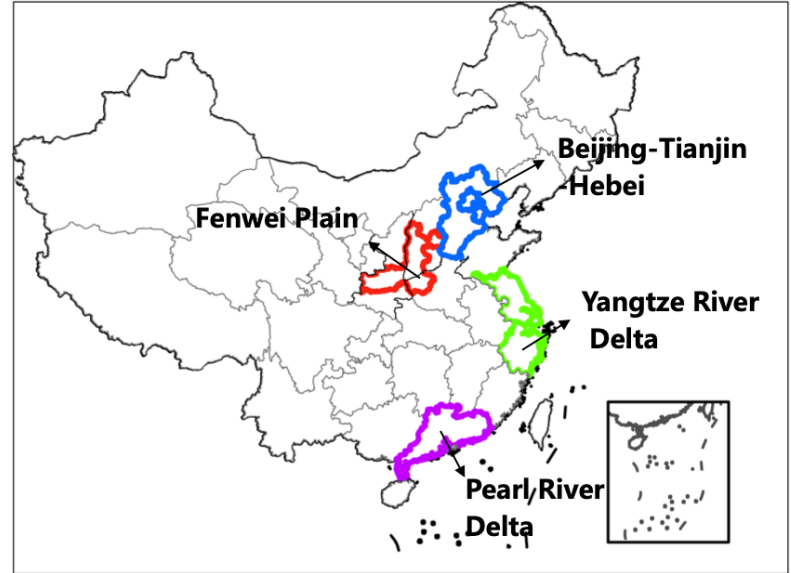

Figure 2. Four key regions are defined in this study: the BeijingTianjin-Hebei region, the Yangtze River Delta region, the Pearl River Delta region, and the Fenwei Plain region.

The following aspects are considered when carrying out an evaluation. First, we examine the ability of InMAP-China to predict $\mathrm{PM}_{2.5}$ concentrations at different emission levels, which will be introduced in Sect. 3.1. We define four key regions here (see Fig. 2) and examine the performance for each region. Second, to examine the ability of the model to quantify source contributions to $\mathrm{PM}_{2.5}$ concentrations, we compare the InMAP-China predictions of the sectoral contributions attributable to power, industry, residential, transportation and agriculture with those based on the CMAQ model, which will be presented in Sect. 3.2. Third, to comprehensively understand the model's performance at a higher spatial resolution, we compare the predictions of $\mathrm{PM}_{2.5}$ concentrations at a $4 \mathrm{~km}$ spatial resolution in the $\mathrm{BTH}$ region modeled by both InMAP-China and the conventional CMAQ model with the observations (see Sect. 3.3). Fourth, focusing on the health impacts, the $\mathrm{PM}_{2.5}$-related premature mortality predicted by InMAP-China is also compared with a mortality estimation based on $\mathrm{PM}_{2.5}$ exposure derived from CMAQ, which is presented in Sect. 3.4.

For the observed $\mathrm{PM}_{2.5}$ concentration data, the annual average observed $\mathrm{PM}_{2.5}$ concentrations in 2017 were calculated using hourly concentration data from the China National Environmental Monitoring Centre (CNEMC; http:// www.cnemc.cn/, last access: 9 December 2021). More than 1400 national monitoring sites for air pollutant concentrations are included in the simulation domain. The statistical parameters used in this study include the correlation coefficient $(R)$, mean bias (MB), mean error (ME), normalized mean bias (NMB), normalized mean error (NME) and rootmean-square error (RMSE). The statistical analyses on the performance of InMAP-China are similar to our previous evaluation of conventional CTMs (Zheng et al., 2015; Wu et al., 2019). 
Table 3. Simulation experiments conducted using InMAP-China.

\begin{tabular}{|c|c|c|c|}
\hline Class & Simulations & Emission input & Physical and chemical parameter input \\
\hline Base & InMAP_TOT & $\begin{array}{l}\text { Five sectoral anthropogenic emissions } \\
\text { and natural emissions }\end{array}$ & $\begin{array}{l}\text { Converted using WRF-CMAQv5.2 } \\
\text { simulation data in 2017; }\end{array}$ \\
\hline High_re & InMAP_BTH & $\begin{array}{l}\text { Five sectoral anthropogenic emissions } \\
\text { and natural emissions at a } 4 \mathrm{~km} \text { reso- } \\
\text { lution in the BTH region }\end{array}$ & remain the same in all simulations. \\
\hline Sec1 & InMAP_POW & Power plant emissions & \\
\hline $\operatorname{Sec} 2$ & InMAP_INDUS & Industrial emissions & \\
\hline $\operatorname{Sec} 3$ & InMAP_TRANS & Transportation emissions & \\
\hline $\operatorname{Sec} 4$ & InMAP_RESI & Residential emissions & \\
\hline Sec5 & InMAP_AGRI & Agricultural emissions & \\
\hline Aba1 & InMAP_RE10 & $\begin{array}{l}\text { Reduce the air pollutant emissions by } \\
10 \% \text { based on InMAP_TOT emissions }\end{array}$ & \\
\hline $\mathrm{Aba} 2$ & InMAP_RE30 & $\begin{array}{l}\text { Reduce the air pollutant emissions by } \\
30 \% \text { based on InMAP_TOT emissions }\end{array}$ & \\
\hline Aba3 & InMAP_RE50 & $\begin{array}{l}\text { Reduce the air pollutant emissions by } \\
50 \% \text { based on InMAP_TOT emissions }\end{array}$ & \\
\hline Aba4 & InMAP_RE70 & $\begin{array}{l}\text { Reduce the air pollutant emissions by } \\
70 \% \text { based on InMAP_TOT emissions }\end{array}$ & \\
\hline Aba5 & InMAP_RE90 & $\begin{array}{l}\text { Reduce the air pollutant emissions by } \\
90 \% \text { based on InMAP_TOT emissions }\end{array}$ & \\
\hline
\end{tabular}

\subsubsection{Experimental design}

We designed 12 simulations to examine the model ability of InMAP-China in this study. Table 3 shows the sequence of simulations.

"InMAP_TOT" represents the baseline simulation with the maximum input of combined emissions. Five sectoral anthropogenic emissions derived from the MEIC inventory, natural emissions derived from the MEGANv2.10 model and Asian emissions outside of mainland China derived from the MIX-2010 inventory are utilized in the simulation. Five sectoral and five abatement simulations are also conducted to examine the ability of InMAP-China to predict concentration changes in response to sectoral emissions and abatement emissions. The emission inputs for these 10 simulations are given in Table 3. The annual average physical and chemical process parameters are calculated based on the output variables of the WRF-CMAQ model, which has already been mentioned in Sect. 2.1.2. Based on the above input, the particle continuity equations are solved by the InMAPChina model to obtain the annual average $\mathrm{PM}_{2.5}$ concentrations at atmospheric steady state. The above simulations are all conducted at a $36 \mathrm{~km}$ spatial resolution across the entirety of mainland of China. Furthermore, another simulation represented by "InMAP-BTH" is conducted at a $4 \mathrm{~km}$ spa- tial resolution over the $\mathrm{BTH}$ region using the anthropogenic emission input data at a $4 \mathrm{~km}$ resolution derived from the MEIC inventory and the natural emission data derived from the MEGANv2.10 model.

To carry out a comparison with the InMAP-China simulations, 11 CMAQ simulations are also performed using the same emission inputs. The hourly $\mathrm{PM}_{2.5}$ concentrations simulated by CMAQ in 2017 are averaged over the entire year. Due to limited computational resources, each simulation is conducted for four representative months (January, April, July and October) in 2017.

\section{Results and discussion}

\subsection{Model performance for $\mathbf{P M}_{2.5}$ concentrations in China}

\subsubsection{Total $\mathbf{P M}_{2.5}$ concentrations}

Figure 3 shows the performance evaluation of total $\mathrm{PM}_{2.5}$ concentrations in the InMAP_TOT simulations. Compared with the observed annual average $\mathrm{PM}_{2.5}$ concentrations, the total $\mathrm{PM}_{2.5}$ concentrations are moderately underpredicted by InMAP-China, with an MB of $-8.1 \mu \mathrm{g} \mathrm{m}^{-3}$ and an NMB of $-18.1 \%$. Compared with the CMAQ predictions, the to- 
(a)

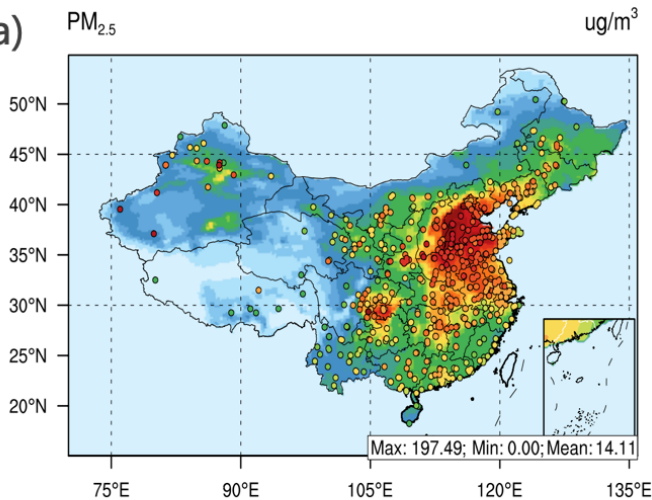

(c)

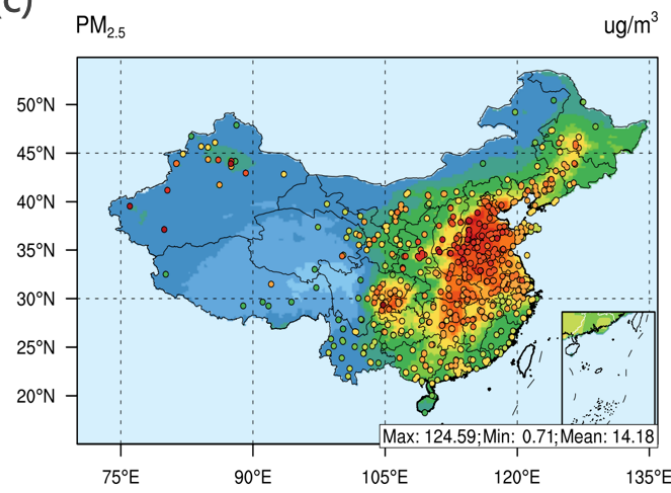

(b)

$\mathrm{PM}_{2.5}$

$\mathrm{ug} / \mathrm{m}^{3}$
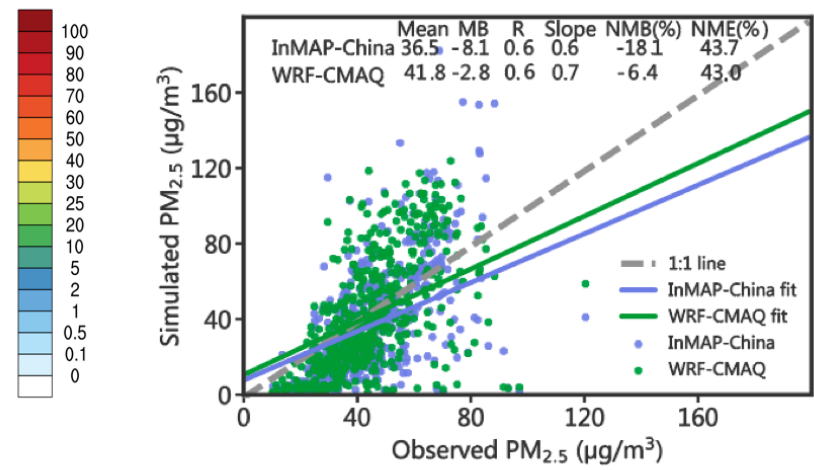

(d)

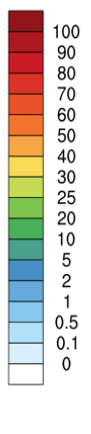

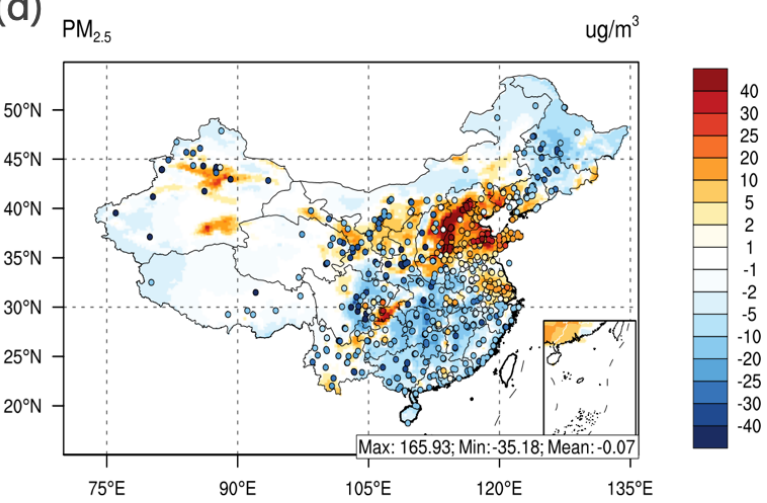

Figure 3. The spatial pattern and statistical metrics of total $\mathrm{PM}_{2.5}$ concentrations predicted by InMAP-China and WRF-CMAQ. Panels (a) and (c) display the spatial patterns of total $\mathrm{PM}_{2.5}$ concentrations predicted by InMAP-China and WRF-CMAQ, respectively. Panel (d) presents the difference in the spatial distribution of the total $\mathrm{PM}_{2.5}$ concentrations predicted by the two models. Panel (b) shows the statistical metrics between the simulated and observed $\mathrm{PM}_{2.5}$. The observed total $\mathrm{PM}_{2.5}$ concentrations are marked as circles in panels (a) and (c). In panel (d), the circle shows the difference between the $\mathrm{PM}_{2.5}$ simulated by InMAP-China and the observed $\mathrm{PM}_{2.5}$. The same color bar is utilized for the contours and the marked circles.

tal $\mathrm{PM}_{2.5}$ concentrations are also underpredicted, with an MB of $-5.3 \mu \mathrm{g} \mathrm{m}^{-3}$, due to the underprediction of primary $\mathrm{PM}_{2.5}$. Consistent air pollutant emissions are employed in the CMAQ and InMAP-China simulations. Therefore, the underpredictions are caused by the different mechanisms in the two models. InMAP-China reproduces the spatial pattern of total $\mathrm{PM}_{2.5}$ concentrations simulated by CMAQ. Notably, significant overpredictions of $\mathrm{PM}_{2.5}$ concentrations can be observed over mountainous areas across northern China, and the complex terrain and high emission intensity increase the challenge of predicting $\mathrm{PM}_{2.5}$ concentrations using the reduced-complexity air quality model in this region.

Figure 4 shows a comparison of $\mathrm{PM}_{2.5}$ compositions. Compared with the CMAQ results, the InMAP-China predictions of $\mathrm{PM}_{2.5}$ compositions are satisfactory, with NMBs for $\mathrm{SO}_{4}^{2-}, \mathrm{NO}_{3}^{-}, \mathrm{NH}_{4}^{+}$and primary $\mathrm{PM}_{2.5}$ of $13 \%,-8 \%$, $-10 \%$ and $-23 \%$, respectively. The predictions of $\mathrm{SO}_{4}^{2-}$, $\mathrm{NO}_{3}^{-}$and $\mathrm{NH}_{4}^{+}$perform better than those of primary $\mathrm{PM}_{2.5}$. Figures 5 and 6 compare the spatial distribution of $\mathrm{PM}_{2.5}$ compositions, and similar overpredictions of $\mathrm{PM}_{2.5}$ compo- sitions can be observed in the mountainous area in northern China.

The ability of InMAP-China to predict $\mathrm{PM}_{2.5}$ compositions is also examined at various emission levels. Figure 7 compares the concentrations of $\mathrm{PM}_{2.5}$ compositions and the proportions of secondary inorganic aerosols (hereafter, SNA) in total $\mathrm{PM}_{2.5}$ concentrations in different scenarios run by the two models. In the InMAP_TOT scenario, the proportion of SNA is $56 \%$, which is extremely close to the $50 \%$ proportion in the WRF-CMAQ simulations. In five emission abatement simulations, the proportion was approximately equal to that in the baseline scenario because the linearly treated chemical reaction relationship of SNA was employed in InMAPChina. However, focusing on the five sectoral emission scenario simulations, a significant difference can be observed, which is mainly caused by the difference in the treatment of chemicals in InMAP-China and CMAQ. In this situation, the impacts on $\mathrm{PM}_{2.5}$ concentrations are distinct due to the nonlinear emission-concentration process. 

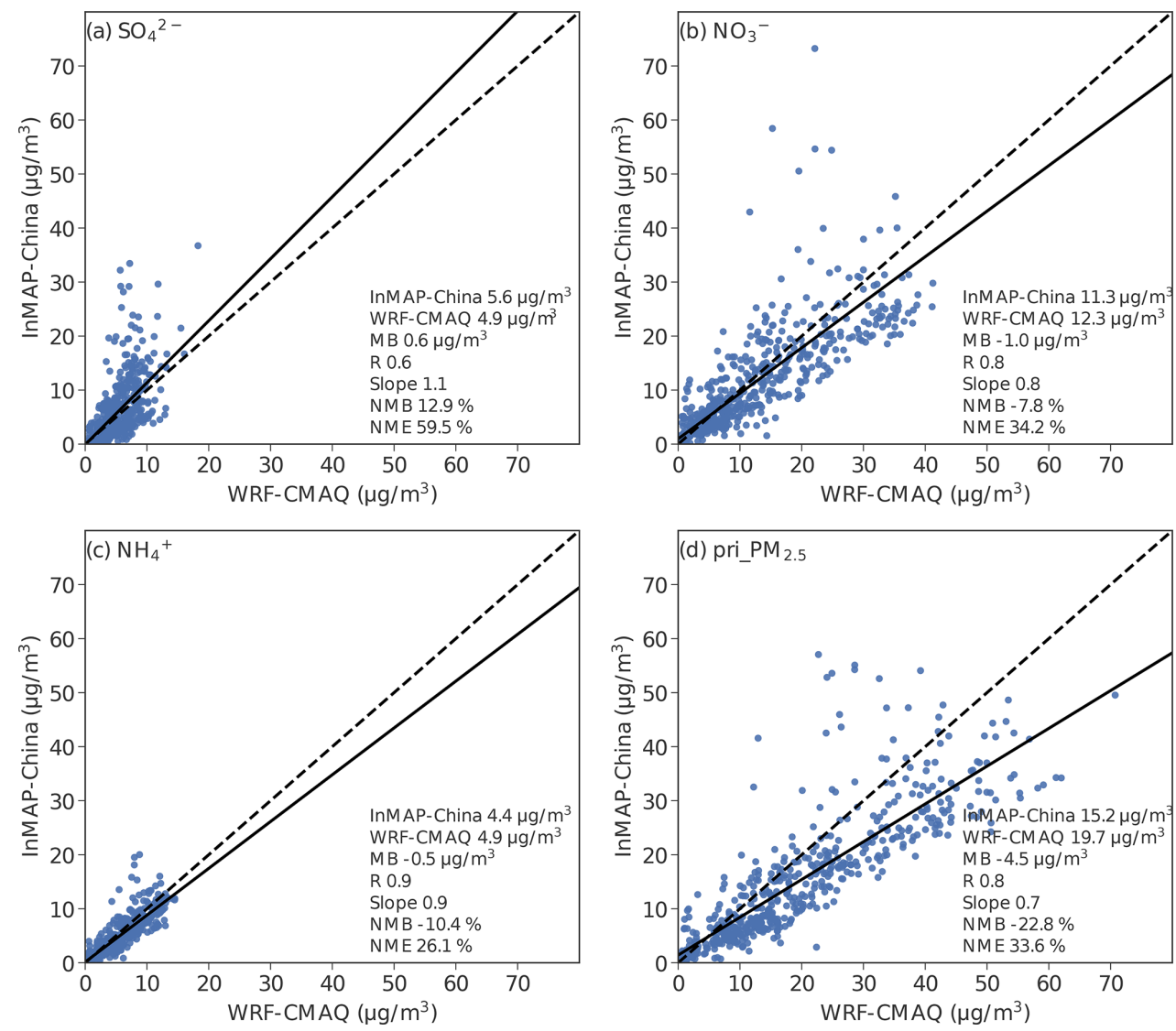

Figure 4. Scatterplot comparing the $\mathrm{PM}_{2.5}$ composition concentration modeled by the InMAP-China and WRF-CMAQ models. Panels (a), (b), (c) and (d) display sulfate, nitrate, ammonium and primary $\mathrm{PM}_{2.5}$, respectively. The statistical metrics are given in the lower right-hand corner of each panel.

\subsubsection{Marginal change in $\mathbf{P M}_{2.5}$ concentrations}

Figure 8 compares the InMAP-China and CMAQ predictions of population-weighted $\mathrm{PM}_{2.5}$ concentrations and $\mathrm{PM}_{2.5}$ compositions for 11 emission scenarios. Marginal changes in air pollutant concentrations are defined as $1 \mu \mathrm{g} \mathrm{m}^{-3}$ by normalizing the population-weighted air pollutant concentrations of each scenario using the largest value among all scenarios modeled by CMAQ. InMAP-China reproduces CMAQ predictions with respect to the marginal change in population-weighted $\mathrm{PM}_{2.5}$ concentrations, with an $\mathrm{NMB}$ of $-12 \%$ and correlations of 0.98 , as shown in Fig. 8a. This performance is similar to that predicted by InMAP in the USA (Tessum et al., 2017).

Figure 8b-f compare the predictions of $\mathrm{PM}_{2.5}$ compositions. InMAP-China predictions of $\mathrm{SO}_{4}^{2-}, \mathrm{NO}_{3}^{-}, \mathrm{NH}_{4}^{+}$and primary $\mathrm{PM}_{2.5}$ agree well with the CMAQ results, but the predictions of secondary organic aerosol (SOA) are the poorest. The marginal changes in $\mathrm{NO}_{3}^{-}$and primary $\mathrm{PM}_{2.5}$ concentrations are moderately underpredicted by InMAP-China, with NMB values of $-13 \%$ and $-21 \%$, respectively. Conversely, the marginal change in the $\mathrm{SO}_{4}^{2-}$ concentrations are overpredicted, with an NMB of $23 \%$. The marginal change in $\mathrm{NH}_{4}^{+}$predicted by InMAP-China agrees well with the CMAQ predictions. Because few reaction pathways of SOA are included in the CB05 mechanism in the CMAQ simulations, SOAs are underpredicted in the entire modeling system.

The regional performance of the changes in $\mathrm{PM}_{2.5}$ and its compositions for the 11 emission scenarios are also examined in this study. Figures S4-S7 show the regional results. Four regions, including the Beijing-Tianjin-Hebei region (BTH), the Yangtze River Delta (YRD), the Pearl River Delta (PRD) and the Fenwei Plain (FWP), are analyzed here (see Fig. 2). At the regional level, the CMAQ predicted marginal changes in population-weighted $\mathrm{PM}_{2.5}$ concentrations, and its composition can be reproduced by InMAPChina, which is similar to the nationwide performance. However, the marginal change in the $\mathrm{SO}_{4}^{2-}$ concentrations over the BTH is significantly overpredicted by InMAP-China, with an NMB of $135 \%$, which is expected to be improved by optimizing the representation of the annual sulfate oxidation rate in this region. 
(a)
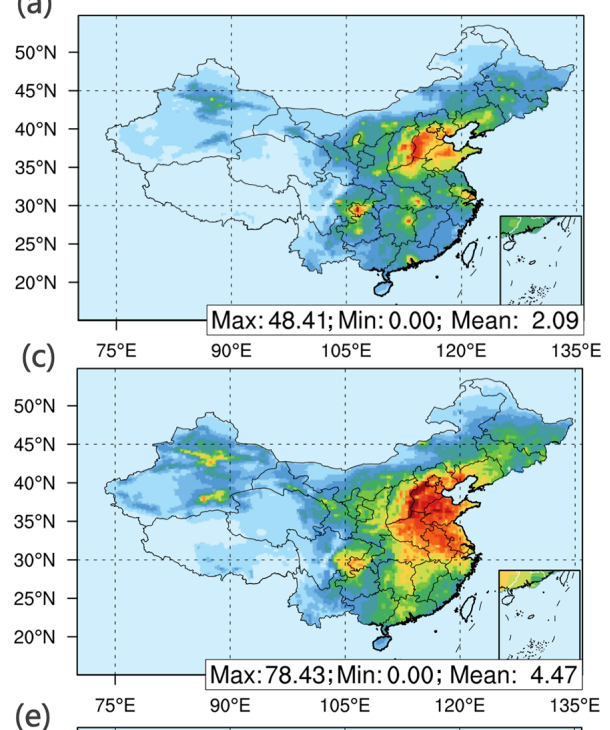

(e)
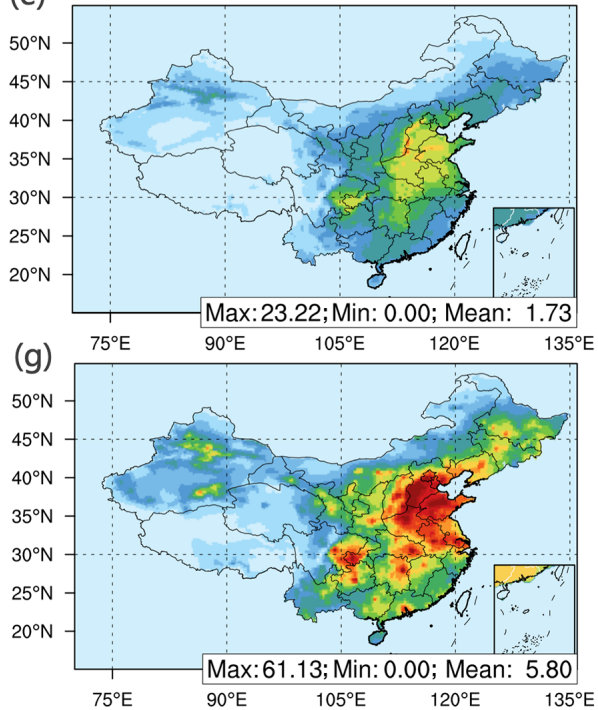

(b)

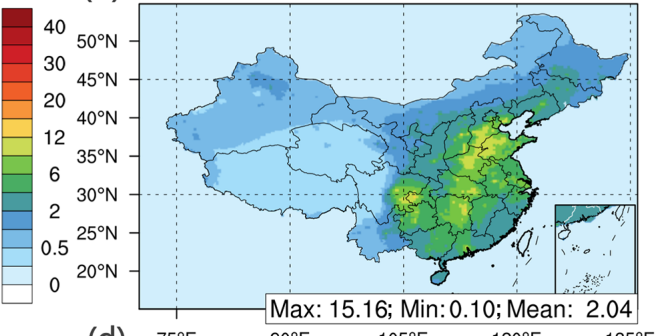

(d)
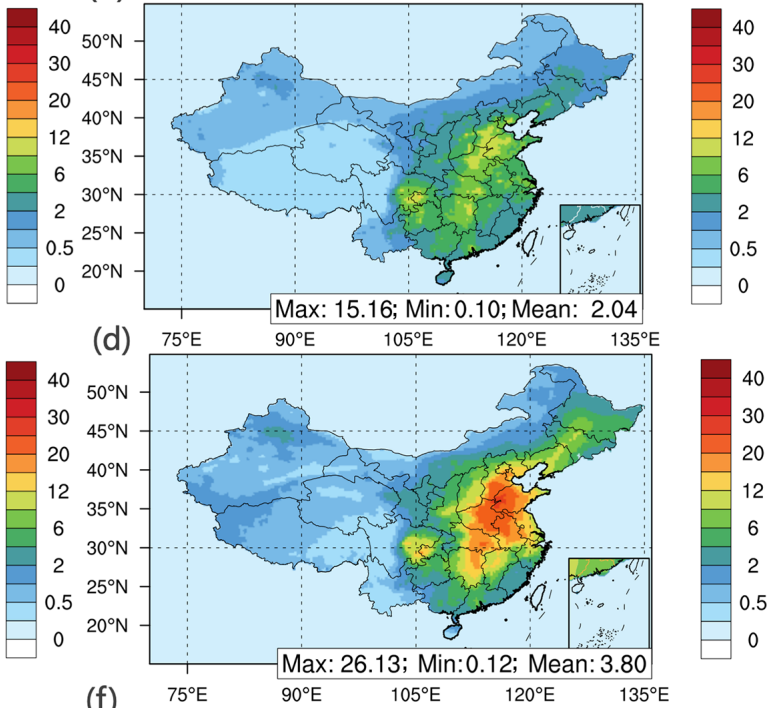

(f)
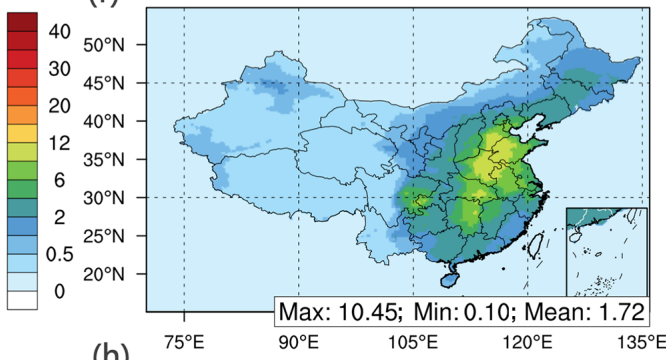

(h)
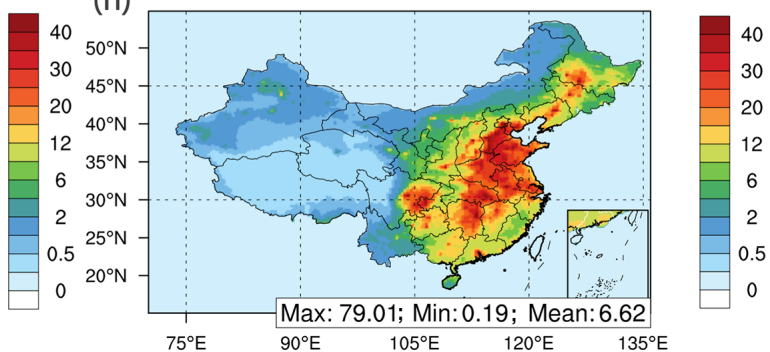

Figure 5. The spatial pattern of $\mathrm{PM}_{2.5}$ compositions modeled by the InMAP-China and WRF-CMAQ models. Panels (a), (c), (e) and (g) present the respective sulfate, nitrate, ammonium and primary $\mathrm{PM}_{2.5}$ simulated by InMAP-China in the InMAP-TOT scenario. Panels (b), (d), (f) and (h) present the corresponding results modeled by WRF-CMAQ.

Table 4. Comparison of the proportions of sectoral contributions to $\mathrm{PM}_{2.5}$ concentrations using InMAP-China and CMAQ.

\begin{tabular}{|c|c|c|c|c|c|c|c|c|c|c|}
\hline \multirow[t]{2}{*}{ Sector } & \multicolumn{2}{|c|}{ National } & \multicolumn{2}{|c|}{ BTH } & \multicolumn{2}{|c|}{ YRD } & \multicolumn{2}{|c|}{ PRD } & \multicolumn{2}{|c|}{ FWP } \\
\hline & CMAQ & $\begin{array}{l}\text { InMAP- } \\
\text { China }\end{array}$ & CMAQ & $\begin{array}{l}\text { InMAP- } \\
\text { China }\end{array}$ & CMAQ & $\begin{array}{l}\text { InMAP- } \\
\text { China }\end{array}$ & CMAQ & $\begin{array}{l}\text { InMAP- } \\
\text { China }\end{array}$ & CMAQ & $\begin{array}{l}\text { InMAP- } \\
\text { China }\end{array}$ \\
\hline Power & $6.9 \%$ & $8.1 \%$ & $6.2 \%$ & $9.4 \%$ & $7.4 \%$ & $8.6 \%$ & $10.4 \%$ & $8.2 \%$ & $7.0 \%$ & $10.0 \%$ \\
\hline Industry & $30.8 \%$ & $35.0 \%$ & $30.2 \%$ & $38.2 \%$ & $33.3 \%$ & $39.1 \%$ & $37.5 \%$ & $35.4 \%$ & $27.7 \%$ & $31.9 \%$ \\
\hline Residential & $25.9 \%$ & $28.1 \%$ & $24.7 \%$ & $28.2 \%$ & $17.9 \%$ & $20.8 \%$ & $19.5 \%$ & $28.4 \%$ & $30.0 \%$ & $33.8 \%$ \\
\hline Transportation & $14.0 \%$ & $17.3 \%$ & $13.4 \%$ & $15.6 \%$ & $15.7 \%$ & $21.2 \%$ & $17.1 \%$ & $17.5 \%$ & $13.2 \%$ & $15.0 \%$ \\
\hline Agriculture & $22.5 \%$ & $11.5 \%$ & $25.5 \%$ & $10.4 \%$ & $25.7 \%$ & $12.4 \%$ & $15.4 \%$ & $11.6 \%$ & $22.0 \%$ & $9.4 \%$ \\
\hline
\end{tabular}


(a)
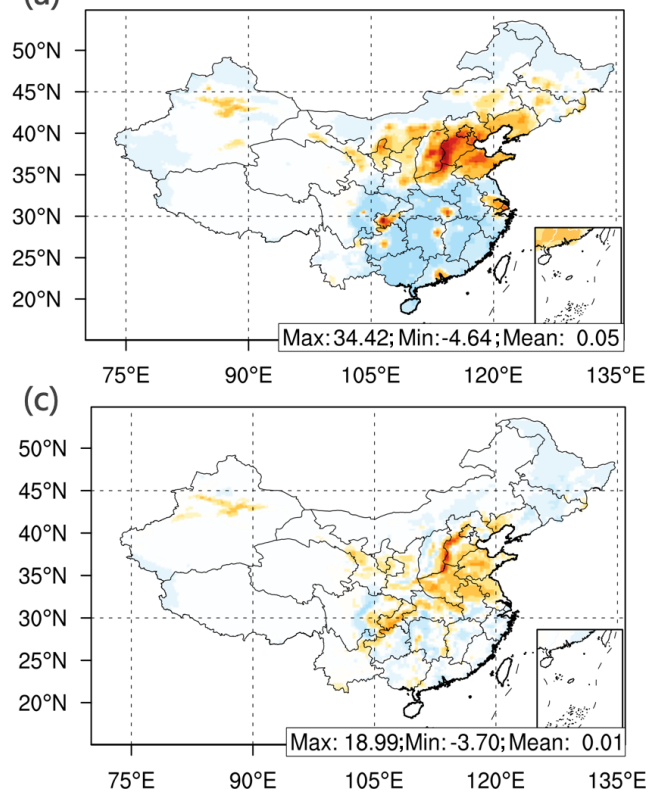

(b)
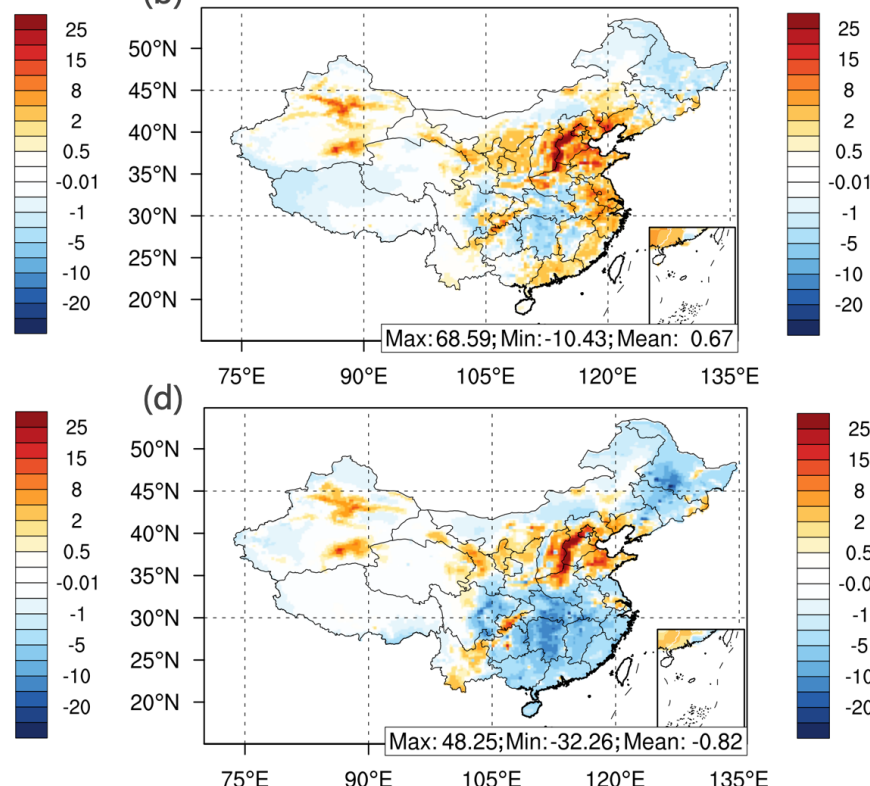

(d)

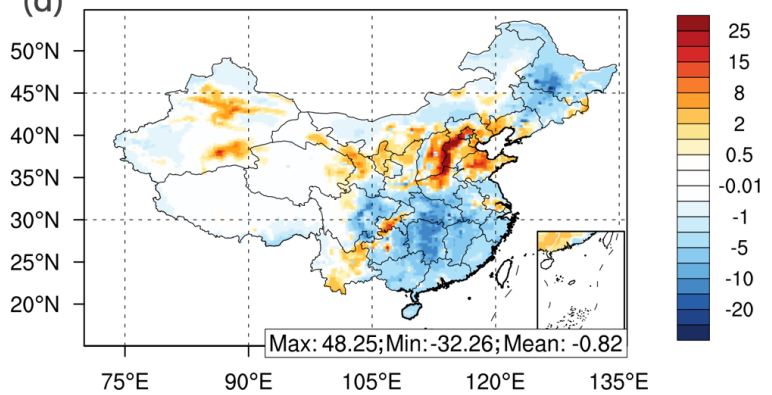

Figure 6. The difference in the spatial pattern of $\mathrm{PM}_{2.5}$ compositions between InMAP-China and WRF-CMAQ. Panels (a), (b), (c) and (d) display sulfate, nitrate, ammonium and primary $\mathrm{PM}_{2.5}$, respectively.

(a)

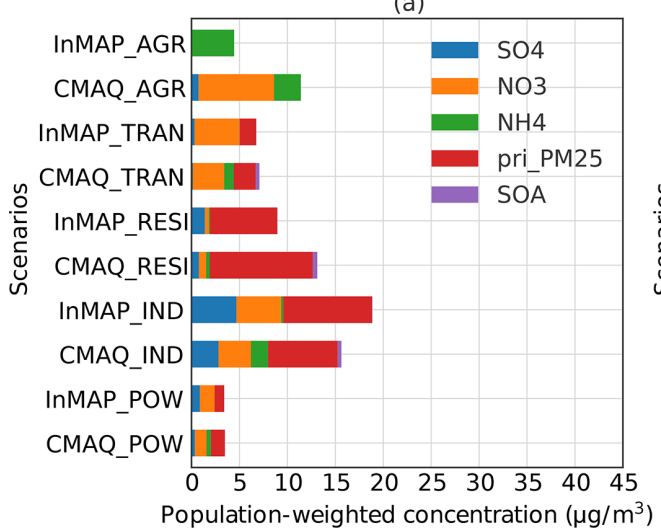

(c)

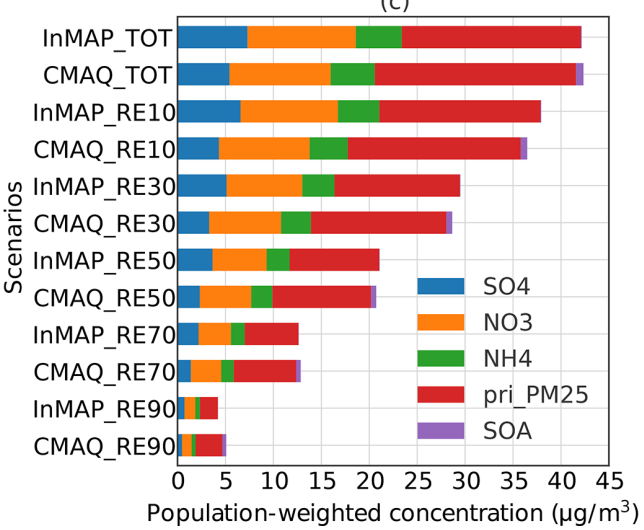

(b)

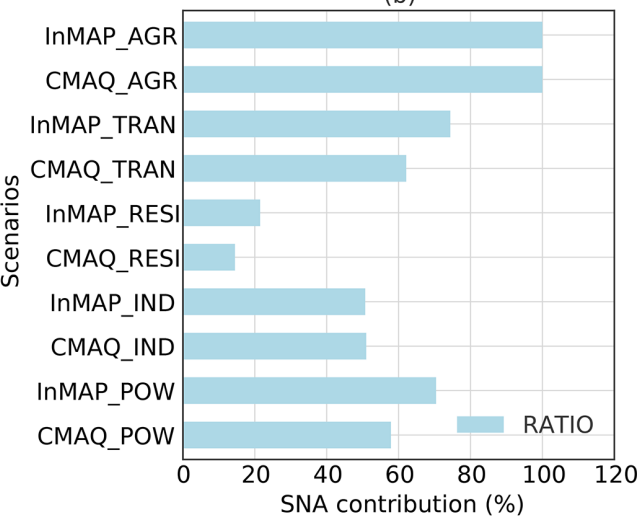

(d)

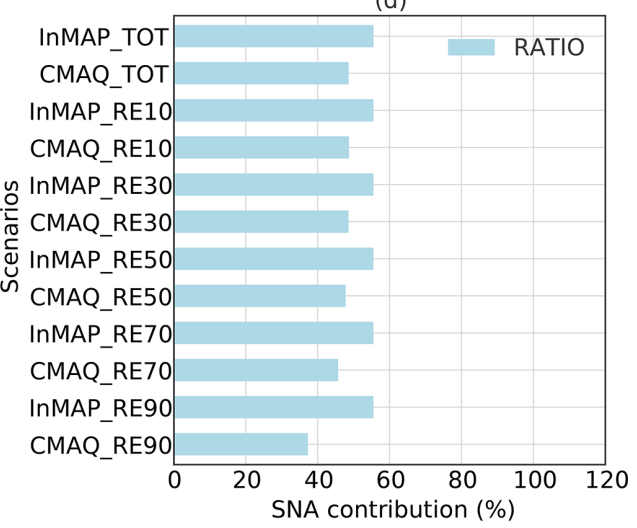

Figure 7. Comparison of $\mathrm{PM}_{2.5}$ component concentrations and SNA contributions in the 11 simulations. Panels (a) and (c) show the modeled $\mathrm{PM}_{2.5}$ compositions: panel (a) presents the results of sectoral emission scenarios, and panel (c) presents the results of the baseline and emission abatement scenarios. Panels (b) and (d) present the SNA contribution (\%) for each scenario. 

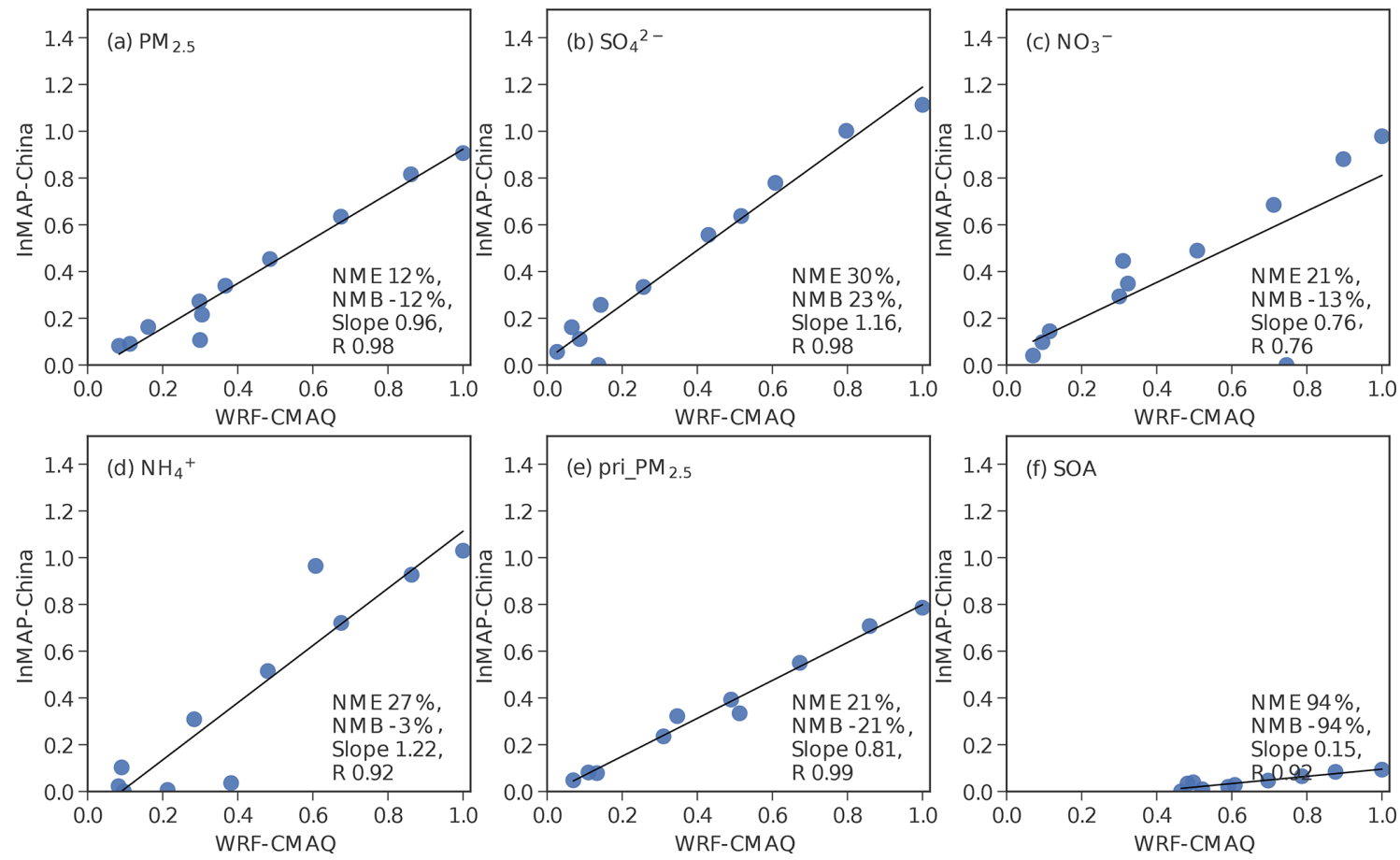

Figure 8. Marginal change in the nationwide annual average population-weighted $\mathrm{PM}_{2.5}$ concentration and its composition as modeled by InMAP-China and WRF-CMAQ for 11 emission scenarios. The population-weighted pollutant concentration for each scenario is normalized using the largest value among all scenarios modeled by CMAQ. The 11 dots represent the 11 scenarios, and the statistical metrics are given in the lower right-hand corner of each panel.

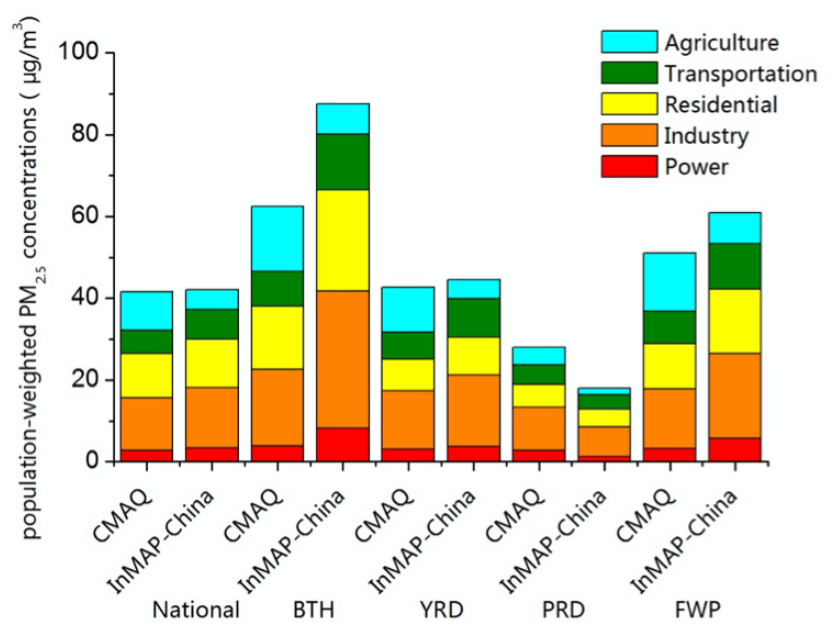

Figure 9. Comparison of source contributions to populationweighted $\mathrm{PM}_{2.5}$ concentrations estimated by the two models.

\subsection{Model performance of source contributions in China}

Figure 9 shows the nationwide and regional-scale contributions of each sector to $\mathrm{PM}_{2.5}$ concentrations, and Table 4 displays the proportions of the sectoral contributions based on the two models. The predictions of the $\mathrm{PM}_{2.5}$ concentration

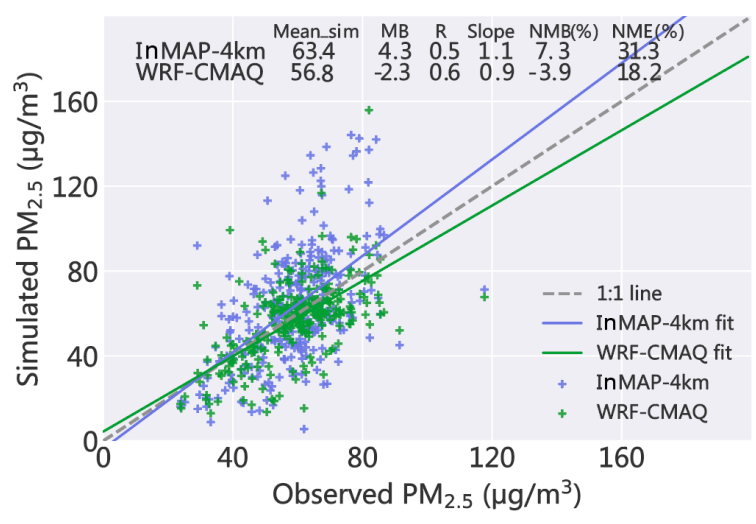

Figure 10. Scatterplot comparing the $\mathrm{PM}_{2.5}$ concentration modeled in the BTH region at a $4 \mathrm{~km}$ spatial resolution by the InMAP-China and WRF-CMAQ models. The statistical metrics are given in the panel.

source contributions in InMAP-China are reliable compared with those based on the CMAQ model, and the difference can be explained.

The results based on the two models indicate that the industrial and residential sectors are the first and second contributors among the five sectors. The contribution of the electricity sector is comparable when using the two models, whereas the contributions of transportation and agricul- 

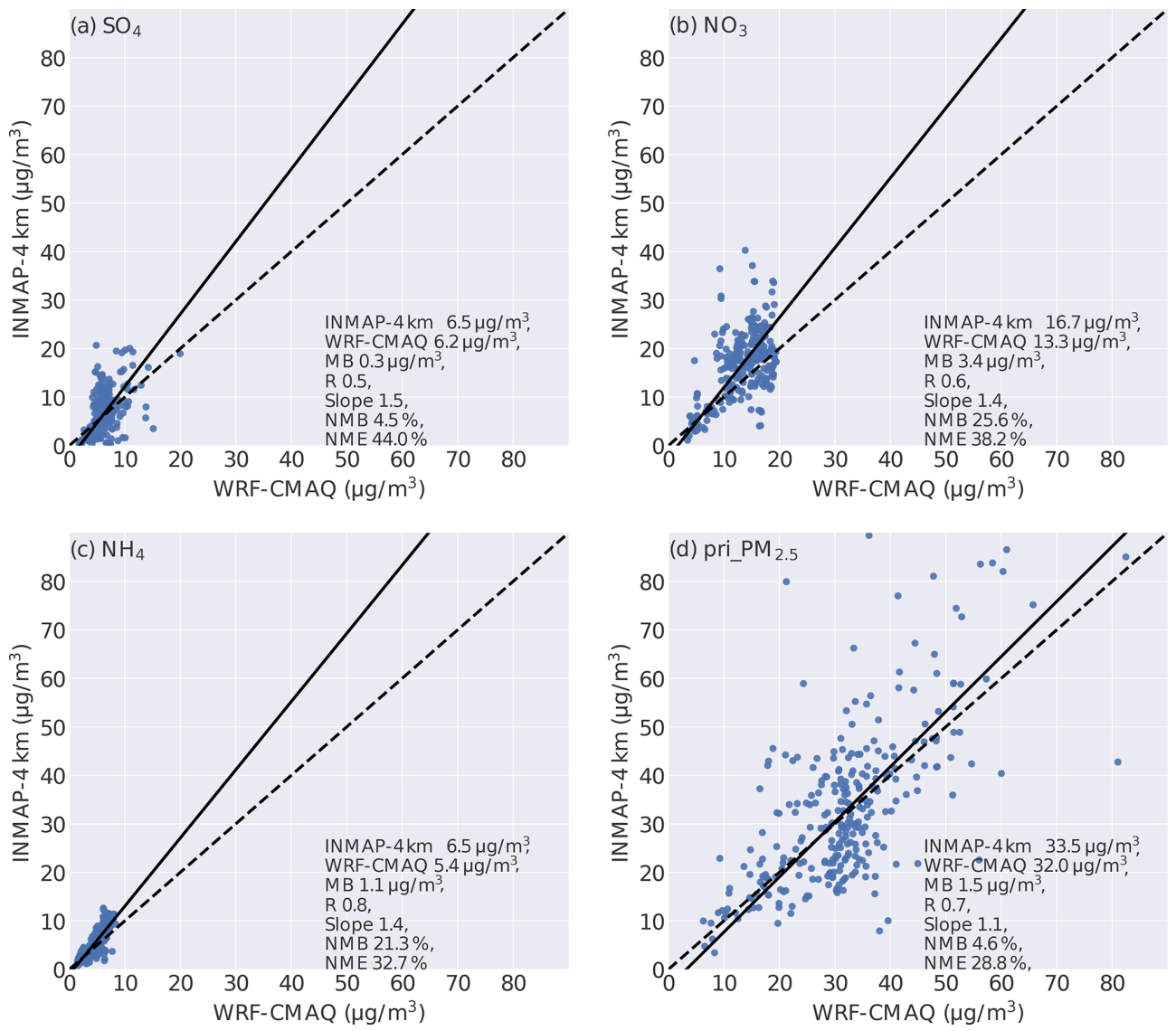

Figure 11. Scatterplot comparing the $\mathrm{PM}_{2.5}$ composition concentration modeled in the $\mathrm{BTH}$ region at a $4 \mathrm{~km}$ spatial resolution by the InMAP-China and WRF-CMAQ models. Panels (a), (b), (c) and (d) display the sulfate, nitrate, ammonium and primary $\mathrm{PM}_{2.5}$, respectively. The statistical metrics are given in the lower right-hand corner of each panel.

ture are moderately different, which is mainly due to the difference in the model mechanism and the treatment of secondary inorganic aerosols in the two models. At the regional scale, the difference in the sectoral contribution caused by the mechanism in the two models is more significant than at the national scale.

\subsection{Model performance of $\mathbf{P M}_{2.5}$ predictions at a higher resolution in the $\mathrm{BTH}$ region}

We also conducted a simulation with a higher spatial resolution of $4 \mathrm{~km}$ in the BTH region using InMAP-China and compared the results to the WRF-CMAQ nested simulation for the same area. Figures 10 and 11 show the performance evaluation of total $\mathrm{PM}_{2.5}$ concentration and the composition in the InMAP_BTH scenario. Compared with the observed annual average $\mathrm{PM}_{2.5}$ concentrations, the total $\mathrm{PM}_{2.5}$ concentrations are moderately overpredicted in InMAP_BTH, with an NMB of $7.3 \%$ and an $R$ value of 0.5 .

Further comparison with the nested CMAQ predictions shows that the total $\mathrm{PM}_{2.5}$ concentrations are also overpredicted by InMAP-China. The predictions of $\mathrm{PM}_{2.5}$ composi- tions in the InMAP_BTH scenario are partially satisfactory with $\mathrm{NMBs}$ for $\mathrm{SO}_{4}^{2-}, \mathrm{NO}_{3}^{-}, \mathrm{NH}_{4}^{+}$and primary $\mathrm{PM}_{2.5}$ of $4.5 \%, 25.6 \%, 21.3 \%$ and $4.6 \%$, respectively. Figure 12 further shows the comparison of the spatial distribution of $\mathrm{PM}_{2.5}$ compositions in the BTH region. The overall spatial distribution pattern of $\mathrm{PM}_{2.5}$ compositions is similarly modeled by the two models; however, an obvious difference can be observed across the mountainous area in the BTH region, for instance, the overpredictions of $\mathrm{PM}_{2.5}$ compositions $\mathrm{SO}_{4}^{2-}$ and $\mathrm{NO}_{3}^{-}$observed near the Taihang Mountains.

\subsection{Model performance for $\mathbf{P M}_{2.5}$-related premature mortality in China}

To examine the performance of the predictions of $\mathrm{PM}_{2.5}$ related premature mortality, a comparison of premature mortality using the $\mathrm{PM}_{2.5}$ predictions from the respective InMAP-China and CMAQ models is performed here. Figure 13 shows the comparison based on two models for all provinces. The results demonstrate that, compared with the premature mortality based on CMAQ, the relative difference 

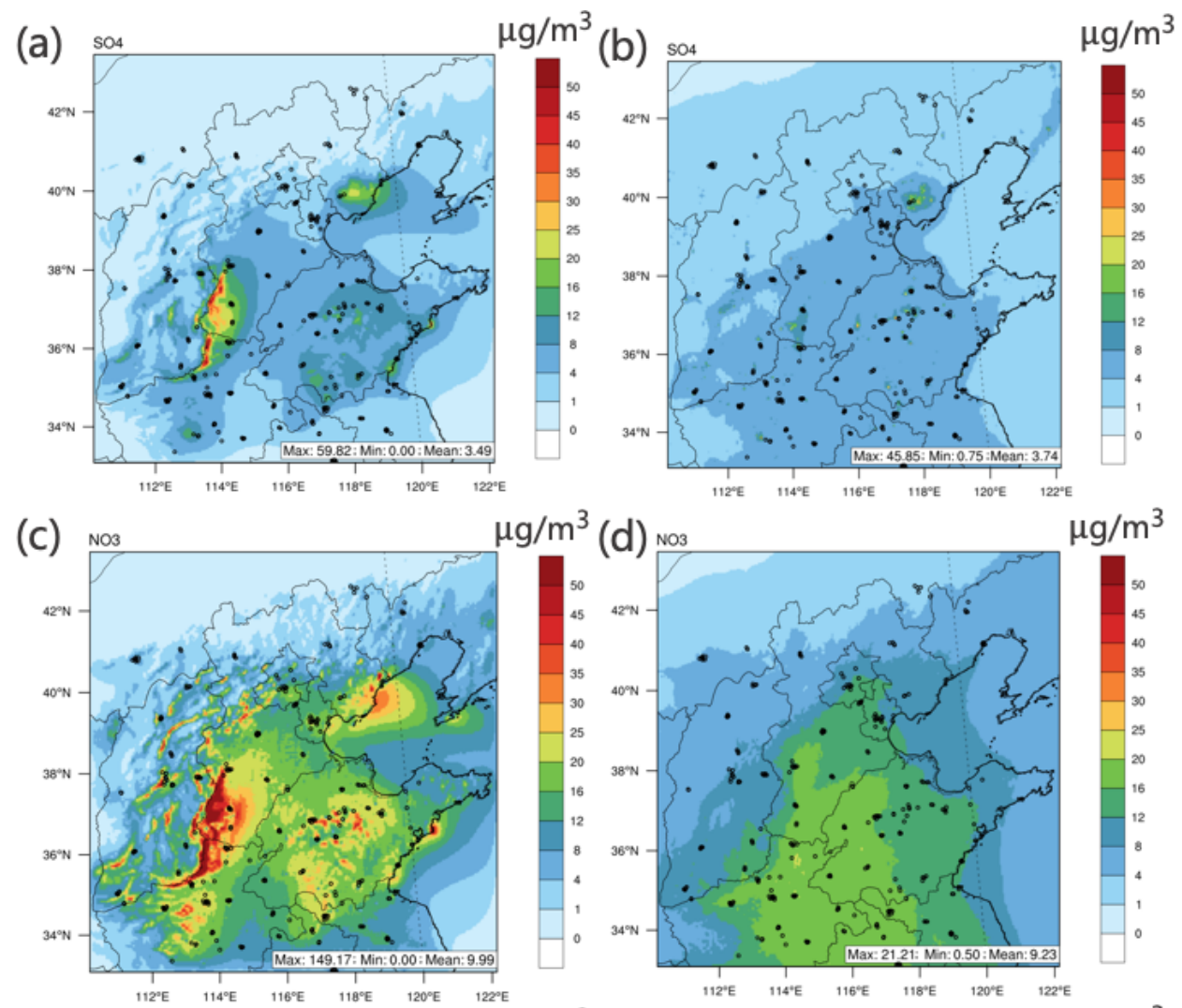

$\mu \mathrm{g} / \mathrm{m}^{3}$ (d)
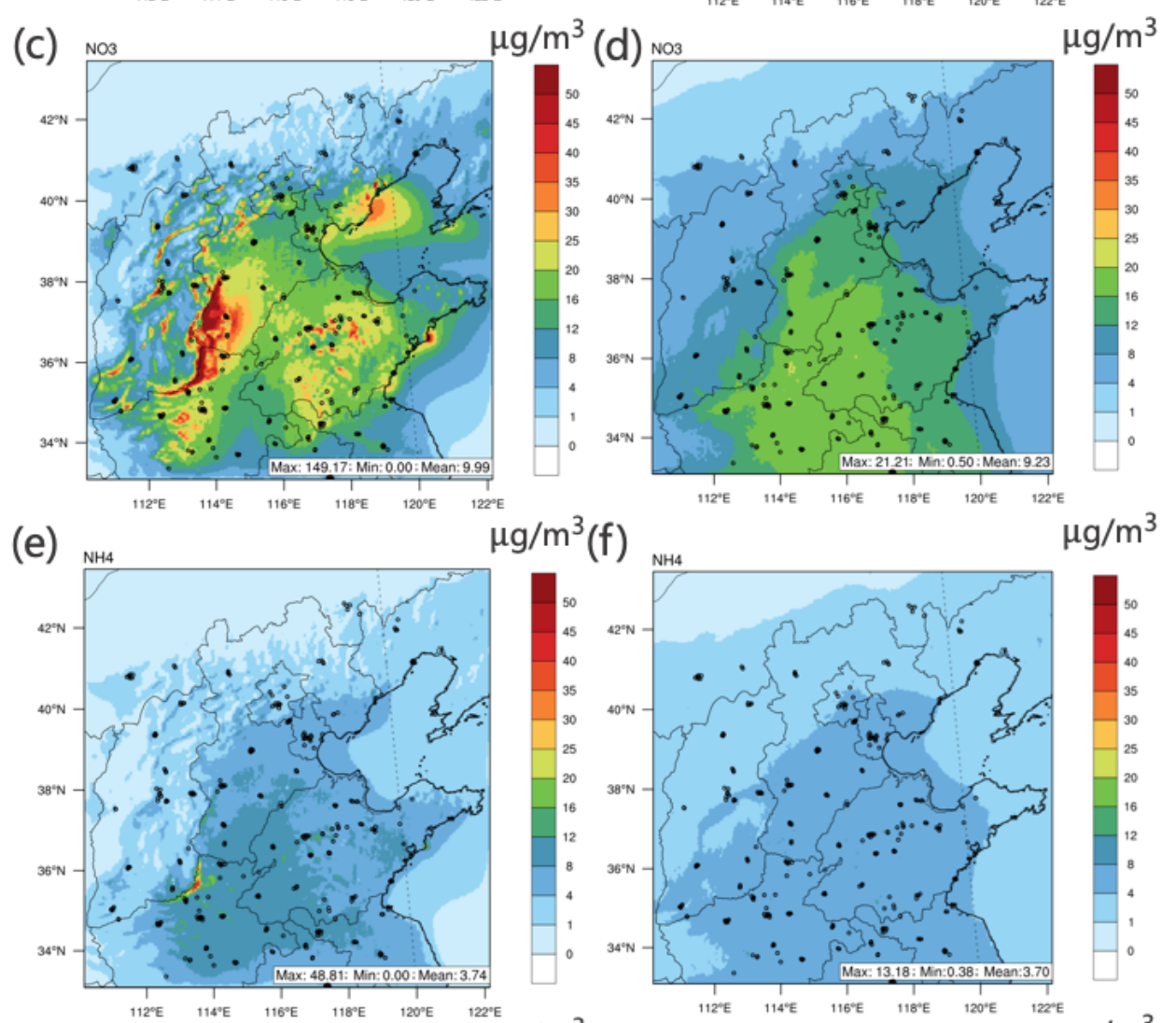

$\mu \mathrm{g} / \mathrm{m}^{3}(\mathrm{f})$
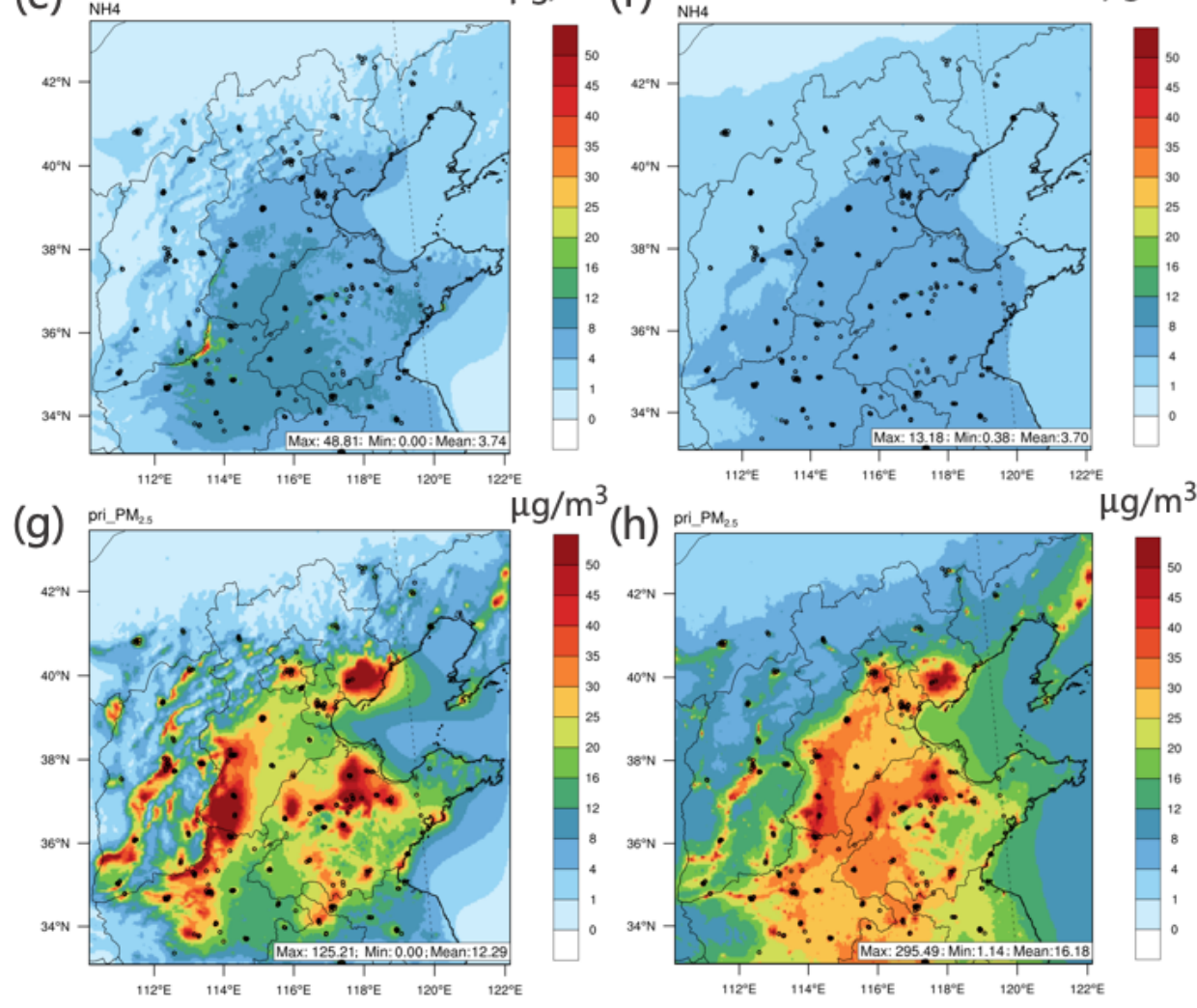

$\mu \mathrm{g} / \mathrm{m}^{3}(\mathrm{~h})$
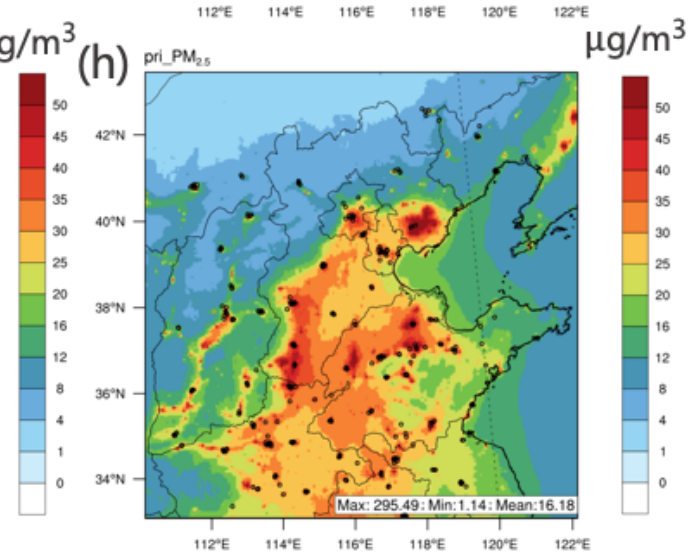

Figure 12. The spatial pattern of $\mathrm{PM}_{2.5}$ compositions simulated in the BTH region at a $4 \mathrm{~km}$ spatial resolution by the InMAP-China and WRF-CMAQ models. Panels (a), (c), (e) and (g) present the respective sulfate, nitrate, ammonium and primary $\mathrm{PM}_{2.5}$, simulated by InMAPChina. Panels (b), (d), (f) and (h) present the corresponding results simulated by WRF-CMAQ. 
(a)

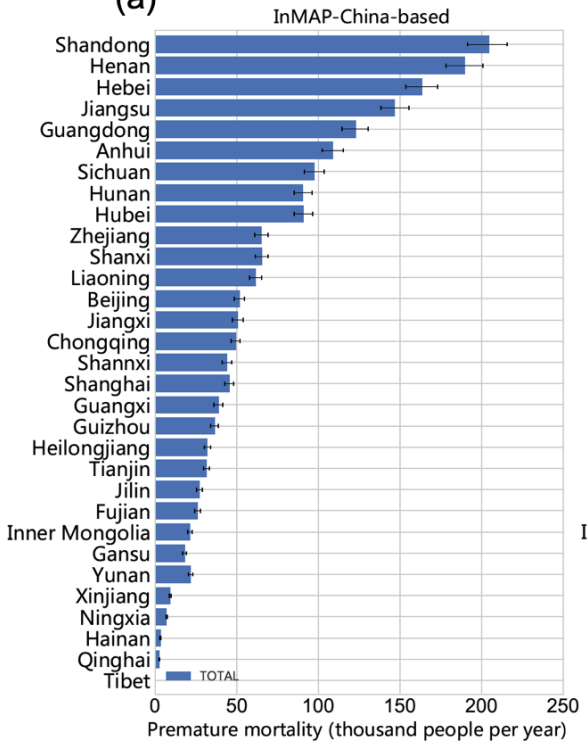

(b)

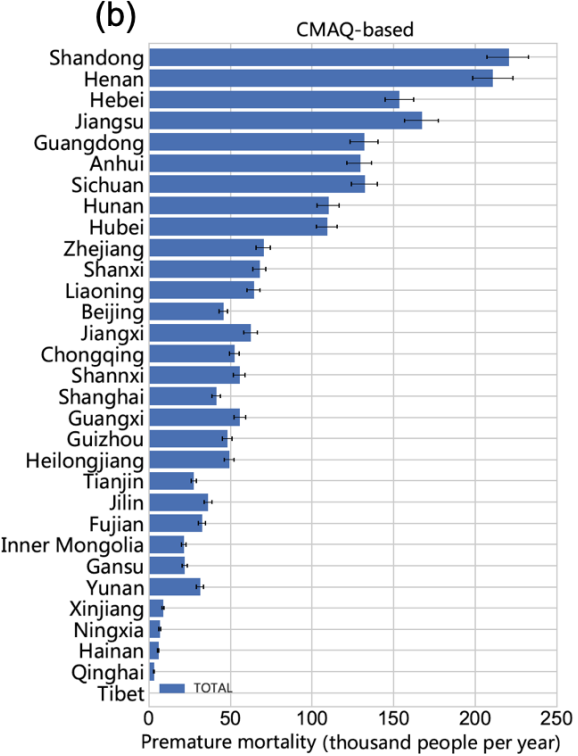

(c)

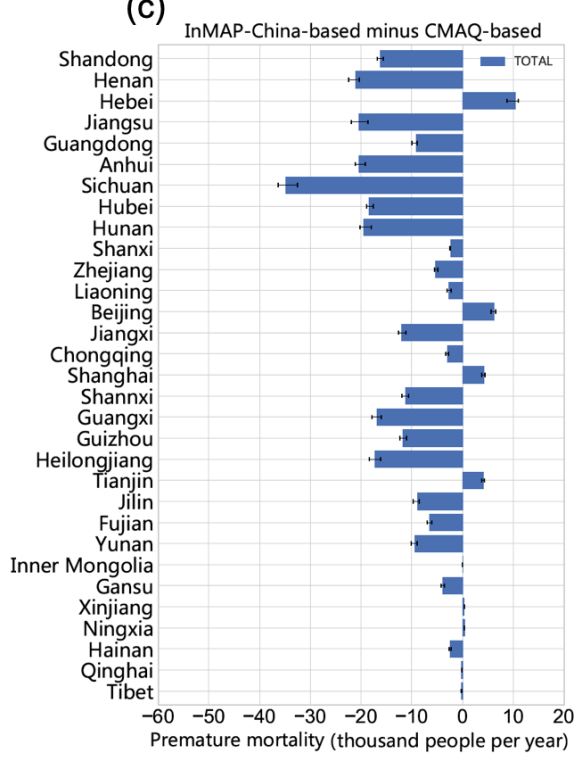

Figure 13. Comparison of $\mathrm{PM}_{2.5}$-related premature mortality using the $\mathrm{PM}_{2.5}$ predictions from the two models. The panels show (a) InMAPChina-based values, (b) CMAQ-based values and (c) the difference between the two models. Note that we use Shanxi and Shannxi to avoid the duplication of province names. Shanxi is adjacent to Hebei Province, whereas Shannxi is adjacent to Gansu Province.

ranges from $-44 \%$ to $15 \%$ at the provincial level due to the difference in the $\mathrm{PM}_{2.5}$ concentrations in the two models.

At the provincial level, the $\mathrm{PM}_{2.5}$-related premature mortality in Beijing, Tianjin, Hebei Province and Shanghai is slightly overpredicted by InMAP-China, with the relative difference ranging from $4 \%$ to $15 \%$. Conversely, for the other majority of provinces, $\mathrm{PM}_{2.5}$-related premature mortality is underpredicted by InMAP-China, with the relative difference ranging from $-3 \%$ to $-44 \%$. Overall, the $\mathrm{PM}_{2.5}$ related premature mortality estimated using InMAP-China was 1.92 million people in 2017. Compared with the CMAQbased estimations, this is an underprediction of 250000 deaths, which stems from underestimations in the total $\mathrm{PM}_{2.5}$ concentrations in the baseline simulation.

\section{Conclusions}

This work develops a reduced-complexity air quality intervention model over China, InMAP-China, and presents a comprehensive evaluation by comparing CMAQ simulations and surface observations. InMAP-China aims at providing a simplified modeling tool to rapidly predict $\mathrm{PM}_{2.5}$ concentrations, owing to emission changes and the health impact of emission sources in China. After the model is established, the total runtime for a new simulation under atmospheric conditions in the year 2017 across mainland China is only $1 \mathrm{~h}$ with a single 24-node CPU. Therefore, the model is temporally efficient when conducting new simulations of $\mathrm{PM}_{2.5}$ concentrations in China. Notably, running WRF-CMAQ simulations is only necessary for the development stage of InMAP-
China. For the application of InMAP-China, we recommend that users select InMAP-China as a prior tool when conducting multiple simulations, for instance, to quantify the $\mathrm{PM}_{2.5}$ concentrations due to hundreds of pollution emitters or to rapidly estimate the $\mathrm{PM}_{2.5}$ concentrations caused by dozens of respective control policies. Furthermore, the variable grid in InMAP-China can also be set to allow a high spatial resolution of $1 \mathrm{~km}$ or even higher in a certain urban area.

InMAP-China has moderately satisfactory performance in this study; however, this model has decreased accuracy compared with conventional CTMs. Overall, InMAP-China satisfactorily predicts total $\mathrm{PM}_{2.5}$ concentrations in the baseline simulation in terms of statistical performance. Compared with the observed $\mathrm{PM}_{2.5}$ concentrations, the $\mathrm{MB}$, NMB and correlations of the total $\mathrm{PM}_{2.5}$ concentrations are $-8.1 \mu \mathrm{g} \mathrm{m}^{-3},-18 \%$ and 0.6 , respectively. The statistical performance is satisfactory for a reduced-complexity air quality model and remains consistent with the performance evaluation in the USA. The underestimation of total $\mathrm{PM}_{2.5}$ mainly comes from the primary $\mathrm{PM}_{2.5}$. Moreover, the spatial pattern of total $\mathrm{PM}_{2.5}$ concentrations can be reproduced in InMAP-China, although an overestimation can be observed over the mountainous area in northern China. The large emission intensity and complex terrain over this region increase the difficulty of modeling concentrations in this area. The predictions of source contributions to $\mathrm{PM}_{2.5}$ concentrations by InMAP-China are comparable with those based on the CMAQ model, and the difference is mainly caused by the uncertainty in the simplification of the chemical process in the InMAP-China. The global version of the reduced-complexity Intervention Model for Air Pollution (Global-InMAP) has 
also been developed and released recently (Thakrar et al., 2021); thus, our results from InMAP-China can provide more accurate results for mainland China.

This study is subject to some limitations and uncertainties. In InMAP-China, the annual average chemical and physical process parameters are calculated using hourly parameters from WRF-CMAQ. Complicated seasonal and daily variations affecting the formation and transportation of particulate matter are challenging to retain. The intensity of advection of the air mass is supposed to be weakened due to the offset of the wind vector in the averaging process, which was also pointed out in a previous study. Moreover, InMAP-China has difficulty predicting SOA concentrations because reaction pathways for SOA are insufficient in this modeling system. Further research is suggested to improve the model performance; for instance, the combination of a machine learning technique and a reduced complexity air quality model may improve the model performance in China.

Code and data availability. The source code of InMAP-China, the user manual, and data related to this study are all available at https://doi.org/10.5281/zenodo.5111961 (Wu, 2021).

Supplement. The supplement related to this article is available online at: https://doi.org/10.5194/gmd-14-7621-2021-supplement.

Author contributions. QZ and RW designed the research, and RW carried it out. RW, CWT and YaZ contributed to model development. $\mathrm{CH}$ and $\mathrm{YZ}$ contributed to data analysis. XQ and SL contributed to data preprocessing. RW and QZ interpreted the results. RW prepared the paper with contributions from all co-authors.

Competing interests. The contact author has declared that neither they nor their co-authors have any competing interests.

Disclaimer. The views expressed in this paper are those of the authors alone and do not necessarily reflect the views and policies of the U.S. EPA. The EPA does not endorse any products or commercial services mentioned in this publication.

Publisher's note: Copernicus Publications remains neutral with regard to jurisdictional claims in published maps and institutional affiliations.

Acknowledgements. This work was supported by the National Natural Science Foundation of China (grant nos. 41625020 and 41921005). It was also funded under Assistance Agreement No. RD835871 awarded by the U.S. EPA to Yale University.
Financial support. This research has been supported by the National Natural Science Foundation of China (grant nos. 41921005 and 41625020) and by the U.S. Environmental Protection Agency (assistance agreement no. RD835871 awarded to Yale University through the SEARCH - Solutions for Energy, AiR, Climate, and Health - Center).

Review statement. This paper was edited by Gunnar Luderer and reviewed by two anonymous referees.

\section{References}

Appel, K. W., Napelenok, S. L., Hogrefe, C., Foley, K. M., Pouliot, G. A., Murphy, B., Heath, N., Roselle, S., Pleim, J., Bash, J. O., Pye, H. O. T., and Mathur, R.: Overview and evaluation of the Community Multiscale Air Quality (CMAQ) modelling system version 5.2, Air Pollution Modeling and its Application XXV, ITM 2016, Springer Proceedings in Complexity, edited by: Mensink, C. and Kallos, G., Springer, Cham, 69-73, https://doi.org/10.1007/978-3-319-57645-9_11, 2018.

Baker, K. R., Amend, M., Penn, S., Bankert, J., Simon, H., Chan, E., Fann, N., Zawacki, M., Davidson, K., and Roman, H.: A database for evaluating the InMAP, APEEP, and EASIUR reduced complexity air-quality modelling tools, Data in Brief, 28, 104886, https://doi.org/10.1016/j.dib.2019.104886, 2020.

Burnett, R., Chen, H., Szyszkowicz, M., Fann, N., Hubbell, B., Pope, C. A., Apte, J. S., Brauer, M., Cohen, A., Weichenthal, S., Coggins, J., Di, Q., Brunekreef, B., Frostad, J., Lim, S. S., Kan, H. D., Walker, K. D., Thurston, G. D., Hayes, R. B., Lim, C. C., Turner, M. C., Jerrett, M., Krewski, D., Gapstur, S. M., Diver, W. R., Ostro, B., Goldberg, D., Crouse, D. L., Martin, R. V., Peters, P., Pinault, L., Tjepkema, M., Donkelaar, A., Villeneuve, P. J., Miller, A. B., Yin, P., Zhou, M. G., Wang, L. J., Janssen, N. A. H., Marra, M., Atkinson, R. W., Tsang, H., Thach, Q., Cannon, J. B., Allen, R. T., Hart, J. E., Laden, F., Cesaroni, G., Forastiere, F., Weinmayr, G., Jaensch, A., Nagel, G., Concin, H., and Spadaro, J. V.: Global estimates of mortality associated with long-term exposure to outdoor fine particulate matter, P. Natl. Acad. Sci. USA, 115, 9592-9597, https://doi.org/10.1073/pnas.1803222115, 2018.

Chang, X., Wang, S., Zhao, B., Xing, J., Liu, X., Wei, L., Song, Y., Wu, W., Cai, S., Zheng, H., Ding, D., and Zheng, M.: Contributions of inter-city and regional transport to $\mathrm{PM}_{2.5}$ concentrations in the Beijing-Tianjin-Hebei region and its implications on regional joint air pollution control, Sci. Total Environ., 660, 11911200, https://doi.org/10.1016/j.scitotenv.2018.12.474, 2019.

Cohen, A. J., Brauer, M., Burnett, R., Anderson, H. R., Frostad, J., Estep, K., Balakrishnan, K., Brunekreef, B., Dandona, L., Dandona, R., Feigin, V., Freedman, G., Hubbell, B., Jobling, A., Kan, H., Knibbs, L., Liu, Y., Martin, R., Morawska, L., Pope III, C. A., Shin, H., Straif, K., Shaddick, G., Thomas, M., van Dingenen, R., van Donkelaar, A., Vos, T., Murray, C. J. L., and Forouzanfar, M. H.: Estimates and 25-year trends of the global burden of disease attributable to ambient air pollution: an analysis of data from the Global Burden of Diseases Study 2015, Lancet, 389, 1907-1918, https://doi.org/10.1016/S0140-6736(17)30505-6, 2017. 
Dimanchevi, E. G., Paltsev, S., Yuan, M., Rothenberg, D., Tessum, C. W., Marshall, J. D., and Selin, N. E.: Health co-benefits of subnational renewable energy policy in the US, Environ. Res. Lett., 14, 085012, https://doi.org/10.1088/1748-9326/ab31d9, 2019.

Doxsey-Whitfield, E., MacManus, K., Adamo, S. B., Susana, B., Pistolesi, L., Squires, J., Borkovska,O., and Baptista, S. R.: Taking advantage of the improved availability of census data: a first look at the gridded population of the world, version 4, Papers in Applied Geography, 1, 226-34, https://doi.org/10.1080/23754931.2015.1014272, 2015.

Gilmore, E. A., Heo, J., Muller, N. Z., Tessum, C. W., Hill, J. D., Marshall, J. D., and Adams, P. J.: An inter-comparison of the social costs of air quality from reduced-complexity models, Environ. Res. Lett., 14, 074016, https://doi.org/10.1088/17489326/ab1ab5, 2019.

Global Burden of Disease Collaborative Network: Global Burden of Disease Study 2017 (GBD 2017) Population Estimates 19502017, Institute for Health Metrics and Evaluation (IHME), Seattle, USA, 2018a.

Global Burden of Disease Collaborative Network: Global Burden of Disease Study 2017 (GBD 2017) Cause-Specific Mortality 1980-2017, Institute for Health Metrics and Evaluation (IHME), Seattle, USA, 2018b.

Goodkind, A. L., Tessum, C. W., Coggins, J. S., Hill, J. D., and Marshall, J. D.: Fine-scale damage estimates of particulate matter air pollution reveal opportunities for location-specific mitigation of emissions, P. Natl. Acad. Sci. USA, 116, 8775-8780, https://doi.org/10.1073/pnas.1816102116, 2019.

Guenther, A. B., Jiang, X., Heald, C. L., Sakulyanontvittaya, T., Duhl, T., Emmons, L. K., and Wang, X.: The Model of Emissions of Gases and Aerosols from Nature version 2.1 (MEGAN2.1): an extended and updated framework for modeling biogenic emissions, Geosci. Model Dev., 5, 1471-1492, https://doi.org/10.5194/gmd-5-1471-2012, 2012.

Heo, J., Adams, P. J., and Gao, H. O.: Reduced-form modelling of public health impacts of inorganic $\mathrm{PM}_{2.5}$ and precursor emissions, Atmos. Environ., 137, 80-89, https://doi.org/10.1016/j.atmosenv.2016.04.026, 2016.

Heo, J., Adams, P. J., and Gao, H. O.: Public health costs accounting of inorganic $\mathrm{PM}_{2.5}$ pollution in metropolitan areas of the United States using a risk-based source-receptor model, Environ. Int., 106, 119-126, https://doi.org/10.1016/j.envint.2017.06.006, 2017.

Hong, C., Zhang, Q., Zhang, Y., Tang, Y., Tong, D., and He, K.: Multi-year downscaling application of two-way coupled WRF v3.4 and CMAQ v5.0.2 over east Asia for regional climate and air quality modeling: model evaluation and aerosol direct effects, Geosci. Model Dev., 10, 2447-2470, https://doi.org/10.5194/gmd-10-2447-2017, 2017.

Li, M., Zhang, Q., Kurokawa, J.-I., Woo, J.-H., He, K., Lu, Z., Ohara, T., Song, Y., Streets, D. G., Carmichael, G. R., Cheng, Y., Hong, C., Huo, H., Jiang, X., Kang, S., Liu, F., Su, H., and Zheng, B.: MIX: a mosaic Asian anthropogenic emission inventory under the international collaboration framework of the MICS-Asia and HTAP, Atmos. Chem. Phys., 17, 935-963, https://doi.org/10.5194/acp-17-935-2017, 2017.

Li, X., Zhang, Q., Zhang, Y., Zheng, B., Wang, K., Chen, Y., Wallington, T. J., Han, W., Shen, W., Zhang, X., and He, K.: Source contributions of urban $\mathrm{PM}_{2.5}$ in the Beijing-Tianjin-
Hebei region: Changes between 2006 and 2013 and relative impacts of emissions and meteorology, Atmos. Environ., 123, 229239, https://doi.org/10.1016/j.atmosenv.2015.10.048, 2015.

Liu, F., Zhang, Q., Tong, D., Zheng, B., Li, M., Huo, H., and He, K. B.: High-resolution inventory of technologies, activities, and emissions of coal-fired power plants in China from 1990 to 2010, Atmos. Chem. Phys., 15, 13299-13317, https://doi.org/10.5194/acp-15-13299-2015, 2015.

Muller, N. Z. and Mendelsohn, R.: Measuring the damages of air pollution in the United States, J. Environ. Econ. Manage., 54, 1-14, https://doi.org/10.1016/j.jeem.2006.12.002, 2007.

Muller, N. Z., Mendelsohn, R., and Nordhaus, W.: Environmental accounting for pollution in the United States economy, Am. Econ. Rev., 101, 1649-1675, https://doi.org/10.1257/aer.101.5.1649, 2011.

National Centers for Environmental Prediction/National Weather Service/NOAA/US Department of Commerce: NCEP FNL Operational Model Global Tropospheric Analyses, continuing from July 1999 Dataset [data set], https://doi.org/10.5065/D6M043C6, 2000.

Reddington, C. L., Conibear, L., Knote, C., Silver, B. J., Li, Y. J., Chan, C. K., Arnold, S. R., and Spracklen, D. V.: Exploring the impacts of anthropogenic emission sectors on $\mathrm{PM}_{2.5}$ and human health in South and East Asia, Atmos. Chem. Phys., 19, 11887 11910, https://doi.org/10.5194/acp-19-11887-2019, 2019.

Sergi, B. J., Adams, P. J., Muller, N. Z., Robinson, A. L., Davis, S. J., Marshall, J. D., and Azevedo, I. L.: Optimizing Emissions Reductions from the U.S. Power Sector for Climate and Health Benefits, Environ. Sci. Technol., 54, 7513-7523, https://doi.org/10.1021/acs.est.9b06936, 2020.

Skamarock, W., Klemp, J., Dudhia, J., Gill, D., Barker, D., Duda, M., Huang, X., Wang, W., and Powers, J.: A description of the Advanced Research WRF Version 3 NCAR technical note, National Center for Atmospheric Research, Boulder, CO, USA, 2008.

Tessum, C. W., Hill, J. D., and Marshall, J. D.: InMAP: A model for air pollution interventions, PLoS One, 12, e0176131, https://doi.org/10.1371/journal.pone.0176131, 2017.

Thakrar, S., Tessum, C., Apte, J., Balasubramanian, S., Millet, D. B., Pandis, S., Marshall, J. D., and Hill, J.: Global, HighResolution, Reduced-Complexity Air Quality Modeling Using InMAP (Intervention Model for Air Pollution), ChemRxiv, https://doi.org/10.33774/chemrxiv-2021-wn21q-v2, 2021.

Thind, M. P. S., Tessum, C. W., Azevedo, I. L., and Marshall, J. D.: Fine Particulate Air Pollution from Electricity Generation in the US: Health Impacts by Race, Income, and Geography, Environ. Sci. Technol., 53, 14010-14019, https://doi.org/10.1021/acs.est.9b02527, 2019.

United States Environmental Protection Agency: National Emission Inventory data, available at: https://www.epa.gov/air-emissions-inventories/ 2011-national-emissions-inventory-nei-data (last access: 9 December 2021), 2011.

$\mathrm{Wu}, \mathrm{R} .:$ A localized version of reduced-complexity air quality intervention model over China (InMAPv1.6.1-China), Zenodo [code], https://doi.org/10.5281/zenodo.5111961, 2021.

Wu, R., Liu, F., Tong, D., Zheng, Y., Lei, Y., Hong, C., Li, M., Liu, J., Zheng, B., Bo, Y., Chen, X., Li, X., and Zhang, Q.: Air quality and health benefits of China's emission control policies on coal- 
fired power plants during 2005-2020, Environ. Res. Lett., 14, 094016, https://doi.org/10.1088/1748-9326/ab3bae, 2019.

Xiao, Q. Y., Geng, G. N., Liang, F. C., Wang, X., Lv, Z., Lei, Y., Huang, X. M., Zhang, Q., Liu, Y., and He, K.: Changes in spatial patterns of $\mathrm{PM}_{2.5}$ pollution in China 20002018: Impact of clean air policies, Environ. Int., 141, 105776, https://doi.org/10.1016/j.envint.2020.105776, 2020.

Zhang, L., Liu, L. C., Zhao, Y. H., Gong, S. L., Zhang, X. Y., Henze, D. K., Capps, S. L., Fu, T. M., Zhang, Q., and Wang, Y. X.: Source attribution of particulate matter pollution over North China with the adjoint method. Environ. Res. Lett., 10, 084011, https://doi.org/10.1088/1748-9326/10/8/084011, 2015.

Zhang, Q., Zheng, Y., Tong, D., Shao, M., Wang, S., Zhang, Y., Xu, X., Wang, J., He, H., Liu, W., Ding, Y., Lei, Y., Li, J., Wang, Z., Zhang, X., Wang, Y., Cheng, J., Liu, Y., Shi, Q., Yan, L., Geng, G., Hong, C., Li, M., Liu, F., Zheng, B., Cao, J., Ding, A., Gao, J., Fu, Q., Huo, J., Liu, B., Liu, Z., Yang, F., He, K., and Hao, J.: Drivers of improved $\mathrm{PM}_{2.5}$ air quality in China from 2013 to 2017, P. Natl. Acad. Sci. USA, 116, 24463-24469, https://doi.org/10.1073/pnas.1907956116, 2019.
Zhao, H., Chen, K., Liu, Z., Zhang, Y., and Zhang, H.: Coordinated control of $\mathrm{PM}_{2.5}$ and $\mathrm{O}_{3}$ is urgently needed in China after implementation of the "Air Pollution Prevention and Control Action Plan", Chemosphere, 270, 129441, https://doi.org/10.1016/j.chemosphere.2020.129441, 2021.

Zheng, B., Zhang, Q., Zhang, Y., He, K. B., Wang, K., Zheng, G. J., Duan, F. K., Ma, Y. L., and Kimoto, T.: Heterogeneous chemistry: a mechanism missing in current models to explain secondary inorganic aerosol formation during the January 2013 haze episode in North China, Atmos. Chem. Phys., 15, 2031-2049, https://doi.org/10.5194/acp-15-2031-2015, 2015. 